\section{A problem-based approach in musculoskeletal ultrasonography: heel pain in adults}

\author{
Yong Hee Kim ${ }^{1}$, Jee Won Chai ${ }^{1,2}$, Dong Hyun Kim ${ }^{1,2}$, Hyo Jin Kim ${ }^{1,2}$, Jiwoon Seo ${ }^{1,2}$ \\ ${ }^{1}$ Department of Radiology, SMG-SNU Boramae Medical Center, Seoul; ${ }^{2}$ Department of \\ Radiology, Seoul National University College of Medicine, Seoul, Korea
}

Musculoskeletal ultrasonography (US) has unique advantages, such as excellent spatial resolution for superficial structures, the capability for dynamic imaging, and the ability for direct correlation and provocation of symptoms. For these reasons, US is increasingly used to evaluate problems in small joints, such as the foot and ankle. However, it is almost impossible to evaluate every anatomic structure within a limited time. Therefore, US examinations can be faster and more efficient if radiologists know where to look and image patients with typical symptoms. In this review, common etiologies of heel pain are discussed in a problem-based manner. Knowing the common pain sources and being familiar with their US findings will help radiologists to perform accurate and effective US examinations.

Keywords: Foot; Ankle; Heel; Pain; Ultrasonography; Ultrasound

Key points: Ultrasonography is a useful imaging modality that can be easily applied to identify the cause of heel pain in adults. Knowing the possible pain sources according to the specific site of pain will enhance the diagnostic quality of the ultrasonography.

\section{Introduction}

Heel pain is a common problem that has a variety of differential diagnoses $[1,2]$. As the treatment is directed toward the cause, it is important to reach an accurate diagnosis, but doing so can be challenging because the potential pain generators are located close to one another $[1,3]$. Therefore, high-resolution ultrasonography (US) can be an excellent tool to assess heel pain, as it can readily evaluate various structures that can produce pain at the heel.

Knowing the anatomic location of the pain may help to narrow the differential diagnosis (Table 1, Fig. 1). Plantar heel pain is usually caused by plantar fasciitis, tears of the plantar fascia, and heel fatpad syndrome. Neuropathy of the inferior calcaneal nerve (Baxter neuropathy) is a less frequently found, but important source of pain in the plantar heel. Common causes of posterior heel pain are Achilles tendinopathy, Haglund deformity with or without retrocalcaneal bursitis. Medial heel pain is commonly caused by tendinopathies, but tarsal tunnel syndrome should always be considered in patients who have medial heel pain, especially when neurologic symptoms are present. Lateral heel pain can be caused by peroneal tendon pathologies, sinus tarsi syndrome, and sural neuropathy. A

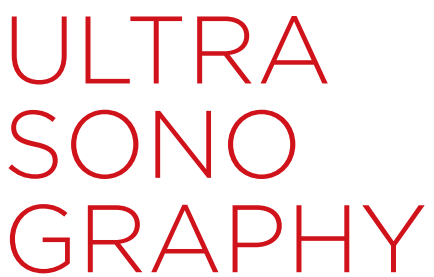

\section{REVIEW ARTICLE}

https://doi.org/10.14366/usg.21069 pISSN: 2288-5919 - elSSN: 2288-5943

Ultrasonography 2022;41:34-52

Received: March 22, 2021

Revised: June 4, 2021

Accepted: June 29, 2021

Correspondence to: Jee Won Chai, MD, PhD, Department of Radiology, SMG-SNU Boramae Medical Center, Seoul National University College of Medicine, 20 Boramae-ro 5-gil, Dongjak-gu, Seoul 07061, Korea

Tel. +82-2-870-2549

Fax. $+82-2-870-3539$

E-mail: chaijw@gmail.com

This is an Open Access article distributed under the terms of the Creative Commons Attribution NonCommercial License (http://creativecommons.org/ licenses/by-nc/4.0// which permits unrestricted noncommercial use, distribution, and reproduction in any medium, provided the original work is properly cited.

Copyright (C) 2022 Korean Society of Ultrasound in Medicine (KSUM)

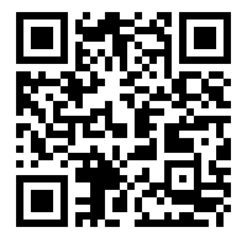

How to cite this article: Kim YH, Chai JW, Kim DH, Kim HJ, Seo J. A problem-based approach in musculoskeletal ultrasonography: heel pain in adults. Ultrasonography. 2022 Jan;41(1):34-52. 


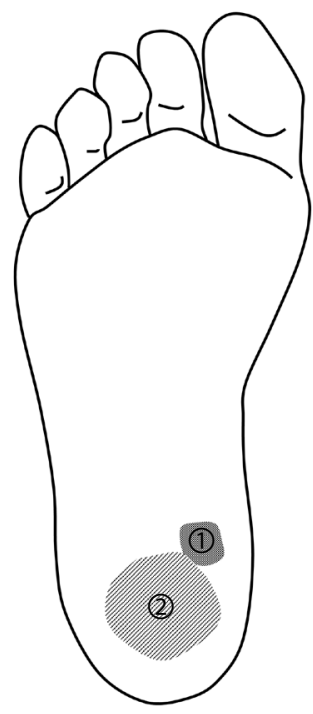

A

Table 1. Possible causes of heel pain listed according to the location of pain with a suggested checklist of structures to evaluate during ultrasonography

\begin{tabular}{|c|c|c|}
\hline Location of pain & Cause of pain & Checklist \\
\hline Plantar & $\begin{array}{l}\text { Plantar fasciitis } \\
\text { Plantar fascia tear } \\
\text { Heel fat pad atrophy } \\
\text { Baxter neuropathy }\end{array}$ & $\begin{array}{l}\text { Plantar fascia } \\
\text { Heel fat pad } \\
\text { Plantar muscle }\end{array}$ \\
\hline Posterior & $\begin{array}{l}\text { Achilles tendinopathy } \\
\text { Bursitis } \\
\text { Haglund's syndrome } \\
\text { Sural neuropathy }\end{array}$ & $\begin{array}{l}\text { Achilles tendon } \\
\text { Deep/superficial } \\
\text { Retrocalcaneal bursae } \\
\text { Sural nerve }\end{array}$ \\
\hline Medial & $\begin{array}{l}\text { Tendinopathies/ } \\
\text { tenosynovitis } \\
\text { Tarsal tunnel syndrome }\end{array}$ & $\begin{array}{l}\text { Flexor tendons } \\
\text { Tarsal tunnel } \\
\text { Plantar muscle }\end{array}$ \\
\hline Lateral & $\begin{array}{l}\text { Peroneal tendinopathy/ } \\
\text { tenosynovitis } \\
\text { Sinus tarsi syndrome } \\
\text { Sural neuropathy }\end{array}$ & $\begin{array}{l}\text { Peroneal tendons } \\
\text { Sinus tarsi } \\
\text { Sural nerve }\end{array}$ \\
\hline Deep and vague & Calcaneal stress fracture & Calcaneus \\
\hline
\end{tabular}

calcaneal fracture can cause deep and vague pain at the heel $[2,4]$.

In this review, common etiologies of chronic heel pain are discussed in a problem-based manner. Knowing the common sources of pain and being familiar with their US findings will help radiologists to perform accurate and effective US examinations. Acute injuries of the hindfoot will not be discussed, because those are beyond the scope of this review.

\section{Patient Positioning}

The US examination to evaluate plantar and posterior heel pain is usually performed with the patient lying on the bed in a prone position with the patient's feet hanging over the edge of the bed $[5,6]$. In this position, the plantar and posterior surface of the heel, including the plantar fascia, heel fat pad, plantar muscles, and the Achilles tendon and its vicinity, can be easily examined. This position also allows the contralateral side to be compared without difficulty. For evaluation of the medial heel, the position of the patient sitting or lying in a supine position with the hip and knee flexed in the frog-leg position is recommended. The lateral heel can be examined in the sitting or supine position with the foot flat on the bed and slightly inverted $[7,8]$. The position of the patient can be modified according to the patient's condition and the examiner's preferences, as well as for a dynamic evaluation.

\section{Plantar Heel Pain}

\section{Plantar Fasciitis}

The plantar aponeurosis, or plantar fascia, is a strong, fibrous investing layer of the sole [9]. The plantar fascia is composed of medial, central, and lateral bands. The thickest central band attaches proximally at the medial tubercle of the calcaneus and fans out distally to the subcutaneous tissue and joint capsules of the second through the fifth metatarsophalangeal joints, as well as the plantar bases of the corresponding proximal phalanges $[10,11]$. The lateral band covers the plantar surface of the abductor digiti minimi muscle and attaches proximally at the lateral tubercle of the calcaneus and distally to the joint capsule at the fifth tarsometatarsal joint. The medial band is much thinner than the other two parts $[10,11]$.

Plantar fasciitis is the most common cause of heel pain, with a 
$10 \%$ lifetime prevalence in the general population, and it accounts for $1 \%$ of all orthopedic outpatient visits $[1,12]$. Patients usually have plantar medial heel pain that peaks either with their first few steps in the morning or after a prolonged period of rest [3]. Although an inflammatory condition is implied by the name "plantar fasciitis," recent studies suggest that it is a degenerative fasciosis lacking inflammation that is caused by repetitive microtrauma and excessive strain [13]. Known risk factors are pes planus, pes cavus, obesity, advanced age, poor footwear, weight-bearing professions, reduced subtalar joint mobility, and tightness of the Achilles tendon or gastrocnemius [3]. The most typically involved site is the calcaneal insertion or proximal third of the central band. However, plantar fasciitis may also involve the middle or distal third of the plantar aponeurosis, which has been reported to be associated with recalcitrant plantar heel pain [14]. The treatment of plantar fasciitis primarily uses conservative modalities, such as rest, structured physical therapy, home stretching exercises, heel cushions, orthoses, ice, nonsteroidal anti-inflammatory drugs, and weight loss [3]. With conservative management, $90 \%$ to $95 \%$ of patients will experience resolution of symptoms within 1 year [2].

The central and lateral band of the plantar fascia can be readily evaluated using US. The central band appears as a uniformly hyperechoic fibrillar structure measuring up to $4 \mathrm{~mm}$ in thickness [15] (Fig. 2). The lateral band is visualized as a thin band that abruptly widens at its insertion, maintaining a uniform hyperechoic fibrillar echotexture throughout its course [16]. Dorsiflexion of the toes during the US exam can facilitate identification of the plantar fascia margin and decrease anisotropy artifacts [17]. However, caution

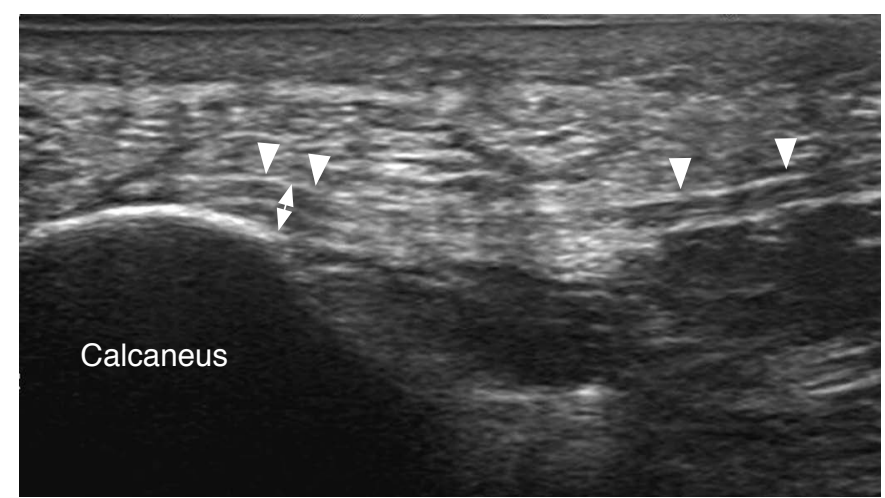

Fig. 2. A 34-year-old woman with normal plantar fascia. In the long-axis view, a normal, uniformly hyperechoic fibrillar echo pattern can be appreciated at the proximal portion of the plantar fascia. The thickness of the plantar fascia measured at the anteroinferior border of the calcaneus was smaller than $4 \mathrm{~mm}$ (double-headed arrow). Note the area of the anisotropy artifact (arrowheads) just distal to the insertion site and mid-portion, because of the normal curved course of the plantar fascia. should be taken in measuring the thickness of plantar fascia in this position, because the plantar fascia thickness decreases with metatarsophalangeal joint extension [18].

Increased thickness of the plantar fascia, decreased echogenicity, loss of fascial edge sharpness, perifascial hypoechogenicity (fluid/ edema) and calcaneal spur/erosion are regarded as common US features of plantar fasciitis $[5,6,17]$ (Fig. 3). From the first attempt to measure the thickness of plantar fascia with US in the patients with plantar fasciitis, a 4-mm thickness has been widely accepted as a criterion for the diagnosis of plantar fasciitis $[17,19]$ at the proximal end of plantar fascia or the anterior margin of the inferior border of the calcaneus with patients in the prone position hanging their feet over the edge of the bed with the ankle dorsiflexed to $90^{\circ}[5,17]$. Although the 4-mm cut-off for the US diagnosis of plantar fasciitis has been validated by many researchers, there are some factors to be considered before applying the thickness criterion alone. Since the plantar fascia thickness can be increased with a higher body mass index in asymptomatic individuals, setting a higher threshold in obese patients has been suggested $[20,21]$. Simultaneously, a much smaller mean thickness of the plantar fascia $(2.9 \mathrm{~mm})$ was also reported in patients with plantar fasciitis diagnosed from a typical clinical history and pain site [22]. Therefore, in addition to the thickness of plantar fascia, other US findings of plantar fasciitis such as reduced echogenicity, loss of fascia edge sharpness, perifascial hypoechogenicity, and calcaneal abnormalities would be helpful in equivocal cases (Fig. 4) [6]. Hyperemia of the plantar fascia on power Doppler US was reported to be present in $27 \%-40 \%$ of plantar fasciitis patients $[20,23]$. One study group reported that

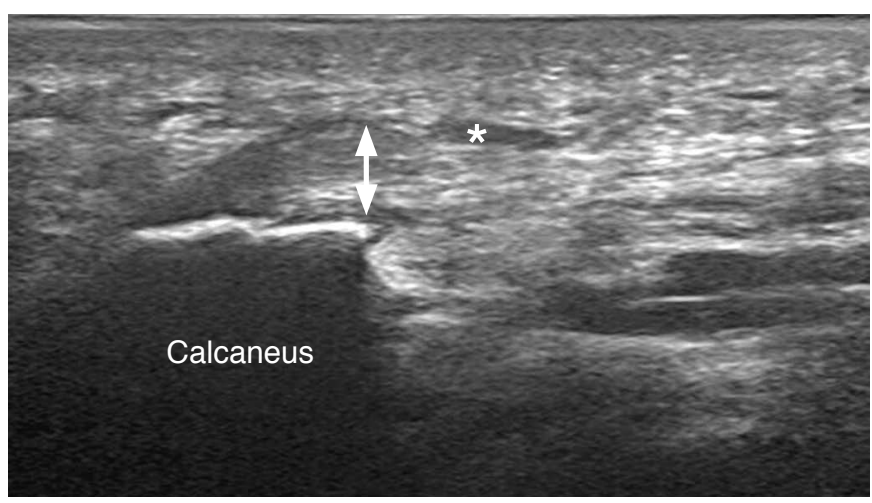

Fig. 3. A 66-year-old woman with plantar fasciitis. In the longaxis view of the proximal plantar fascia, fusiform thickening, hypoechogenicity of the superficial fibers, and perifascial hypoechogenicity (asterisk) are noted. The thickness of the plantar fascia in this case was greater than the 4-mm cut-off for diagnosing plantar fasciitis (double-headed arrow). 


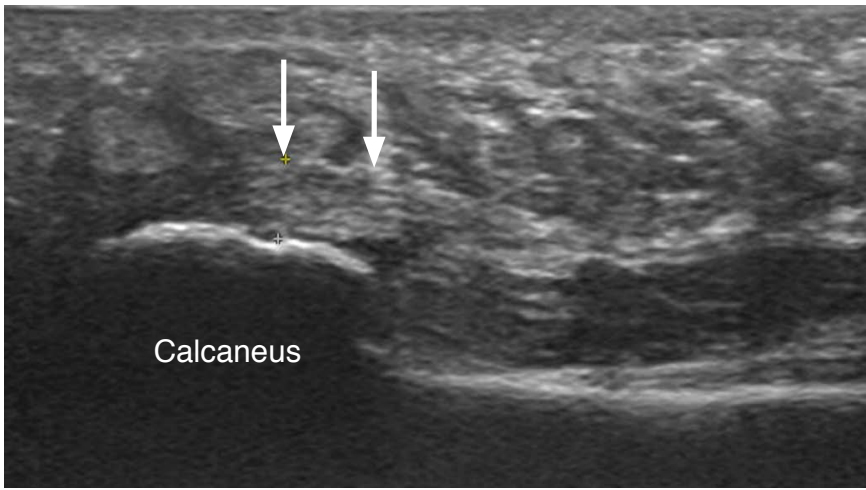

A

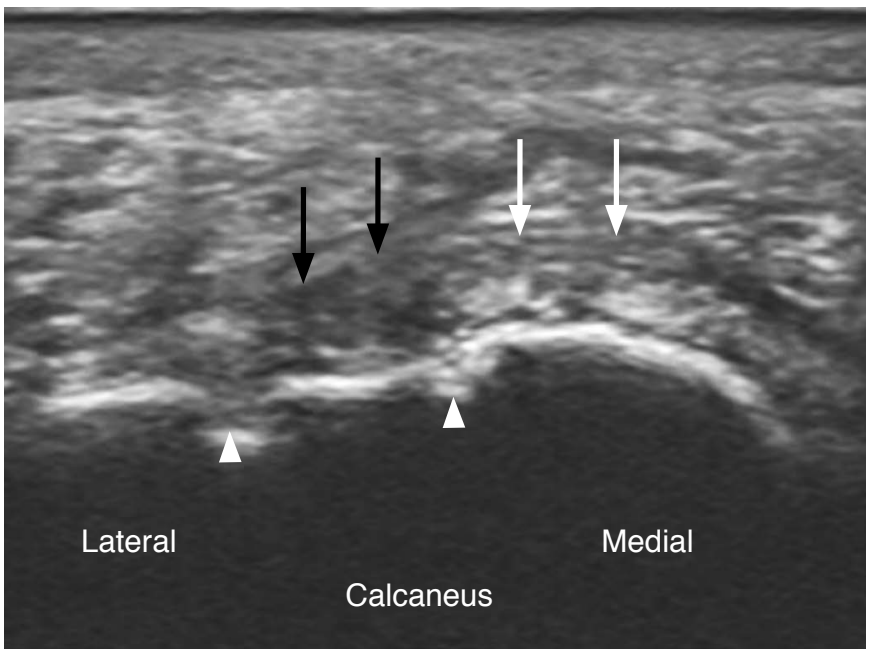

C

plantar fascia hyperemia indicated the presence of acute-phase disease and the degree of hyperemia was correlated with the pain score [23], but such a relationship was not found in a more recent study conducted by another group [20].

The differential diagnosis of plantar fasciitis includes plantar fibromatosis and tear of the plantar fascia. Plantar fibromatosis is a benign fibroproliferative disorder that usually manifests as a painless lump in the midfoot or forefoot region $[24,25]$. However, it occasionally causes pain from direct pressure by the arch of the shoe or from medial plantar nerve irritation by compression [26]. Plantar fibroma appears as a hypoechoic fusiform nodular thickening within the central band of the plantar fascia and may extend beyond the superficial border. The main differentiating feature of plantar fasciitis from plantar fibroma is the location involved; the proximal portion near the calcaneal attachment site in plantar fasciitis and the middle to distal portion of the fascia in plantar fibromatosis. Furthermore, the typical finding of superficial involvement (one-half to two-thirds in the thickness of plantar fascia) of plantar fibromatosis (Fig. 5) can help distinguish it from plantar fasciitis, which usually involves the

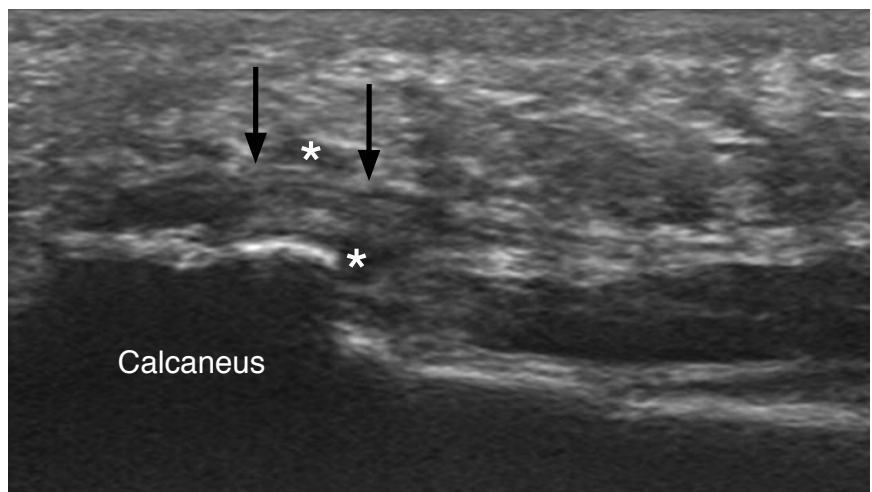

B

Fig. 4. A 52-year-old woman with plantar fasciitis.

A. Long-axis view of the proximal plantar fascia, medial portion is shown. The plantar fascia appeared normal with a hyperechoic fibrillar appearance (white arrows). B. Long-axis view of the proximal plantar fascia, central portion is shown. The plantar fascia revealed decreased echogenicity (black arrows), with a perifascial hypoechoic area (asterisks) suggesting plantar fasciitis. C. Short-axis view of the proximal plantar fascia is shown. Localized hypoechoic changes (black arrows) are noted at the central portion of the plantar fascia accompanied by cortical erosion at the calcaneus (white arrowheads). The thickness of plantar fascia in this case was not greater than the 4-mm cut-off for diagnosing plantar fasciitis. Note the relatively normal-looking plantar fascia (white arrows) at medial portion.

whole thickness of the plantar fascia, in unclear cases [26].

Sabir et al. [6] reported $80.9 \%$ sensitivity and $85.7 \%$ specificity of US to diagnose plantar fasciitis when it was correlated to magnetic resonance imaging (MRI) findings as a reference standard in 2005. However, US may have more value than reported considering the cost, accessibility, and increased resolution with recent technical developments, though there are not sufficient studies on this topic. According to the recently released American College of Radiology (ACR) appropriateness criteria for chronic foot pain [27], the use of either US or MRI without contrast for plantar fasciitis is categorized as "usually appropriate".

\section{Tear of the Plantar Fascia}

Tear of the plantar fascia is much less common than plantar fasciitis but occurs in a similar patient population [16]. It can occur in acuteon-chronic fashion in patients with pre-existing plantar fasciitis, or in acute fashion in patients without a history of plantar fasciitis. Acute-on-chronic type plantar fascia rupture is often preceded by a glucocorticoid injection [28], and acute rupture of the plantar fascia 


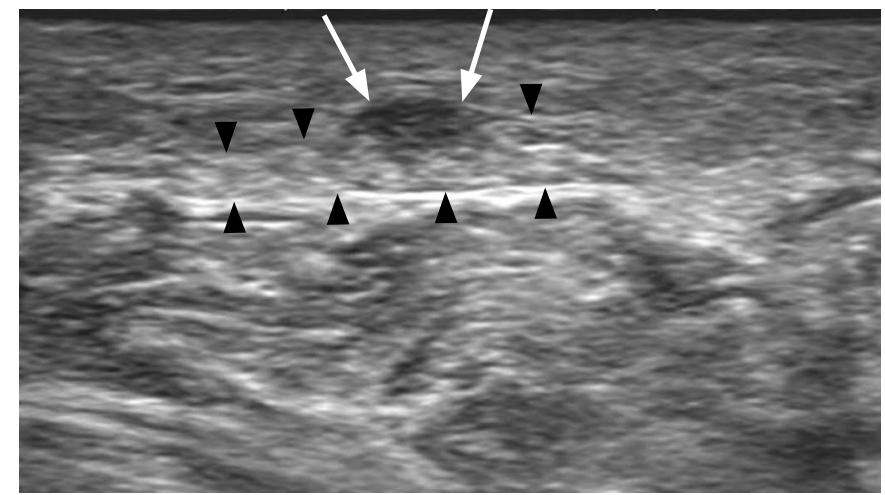

A

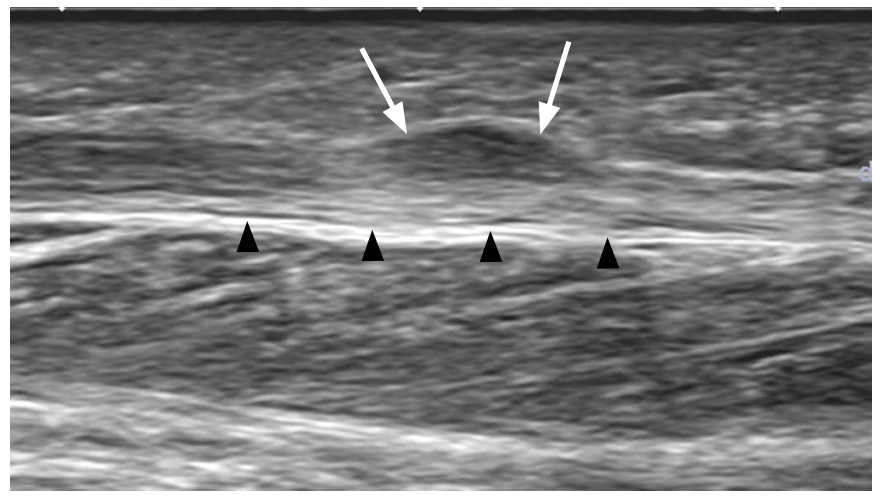

B

Fig. 5. A 70-year-old woman with plantar fibromatosis.

A. Short-axis view of the plantar fascia at the midfoot level shows a relatively well-defined hypoechoic lesion (white arrows) involving the superficial plantar fascia. Note that the lesion is located within the plantar fascia (black arrowheads). B. Long-axis view of the mass shows a spindle-shaped hypoechoic lesion (white arrows) involving the superficial one-half of the plantar fascia. The mass is protruding superficially, with the undersurface of the plantar fascia (black arrowheads) remaining flat.

often affects competitive or amateur athletes [29].

Acute tears of the plantar fascia can occur both at its proximal third and at the mid-substance, which can be noted as disruption of the fibers with surrounding or intervening fluid [16]. Chronic tears can be seen as a nodular thickening of the plantar fascia with loss of fibrillar continuity, often affecting the superficial fibers more than the deep ones [30]. In cases where it is difficult to differentiate partial plantar fascia tears from severe plantar fasciitis, one of the clues is the location of the lesion. Tears of the plantar fascia tend to involve the area 2 to $3 \mathrm{~cm}$ distal from the calcaneal insertion (Fig. 6), whereas plantar fasciitis is most common at the calcaneal attachment [31]. A dynamic evaluation with dorsiflexion of the great toe can also aid in differentiation by demonstrating the gap of the torn fascia in recent injuries [26,32]. The same maneuver can be used to ascertain whether a tear of the plantar fascia is partial or full-thickness [26].

\section{Heel Fat Pad Atrophy}

The heel fat pad (HFP) is located beneath the calcaneus and composed of closely packed chambers of specialized fat surrounded by tough septa of collagen and elastin fibers [3,33]. On US, a normal HFP appears as uniform heterogeneity in which circular or ovoid hypoechoic fat pockets are separated by hyperechoic fibrous septa, with an uncompressed thickness measuring 12-28 mm on US [33]. Because the HFP serves as a shock absorber, its atrophy results in deep, radiating pain at the plantar heel typically involving the central weight-bearing portion of the calcaneal tuberosity, and the pain is usually exacerbated by walking on hard surfaces with bare feet [3].

HFP atrophy is the second leading cause of plantar heel pain $[34,35]$. However, little research has investigated the pathogenesis

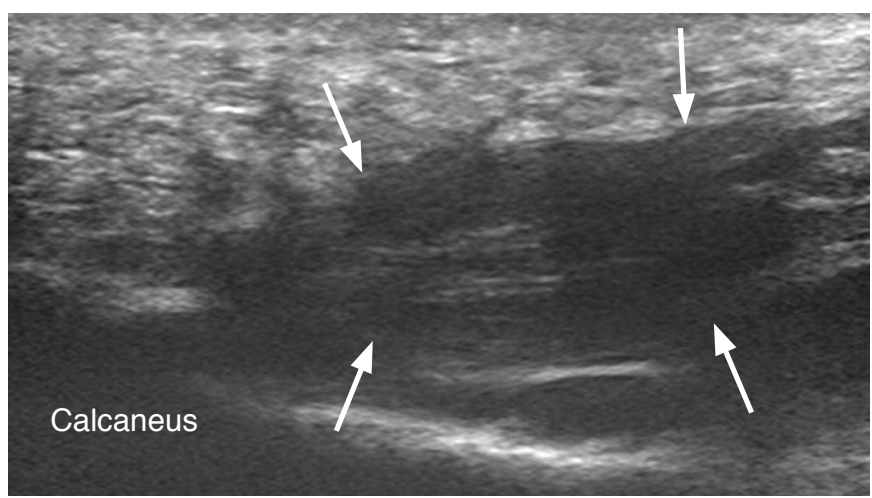

Fig. 6. A 48-year-old man with a chronic plantar fascial tear. He had acute extreme pain at the plantar heel when he slammed on the brakes during a traffic accident 2 years ago. Long-axis view of the proximal plantar fascia shows marked thickening, blurred margin, and disruption of the normal fibrillar pattern (arrows). The abnormality of the plantar fascia is most pronounced at $2-3 \mathrm{~cm}$ distal to the calcaneal insertion, which is the typical site for a plantar fascial tear.

or imaging features of this condition, which is described using a variety of inconsistent terms, such as heel pad syndrome, subcalcaneal inflammatory lesion, and subcalcaneal adventitial bursitis [36-38].

In US studies of HFP in patients with underlying systemic inflammatory disorders, the abnormal findings of HFP were reported as an "inflammatory-edematous" pattern (intense hypoechoic area within the HFP with increased compressibility, sometimes with increased thickness in the unloaded position) (Fig. 7) and a "degenerative-atrophic" pattern (increased echogenicity with thinning of the fat pad). These HFP lesions are thought to be in the 


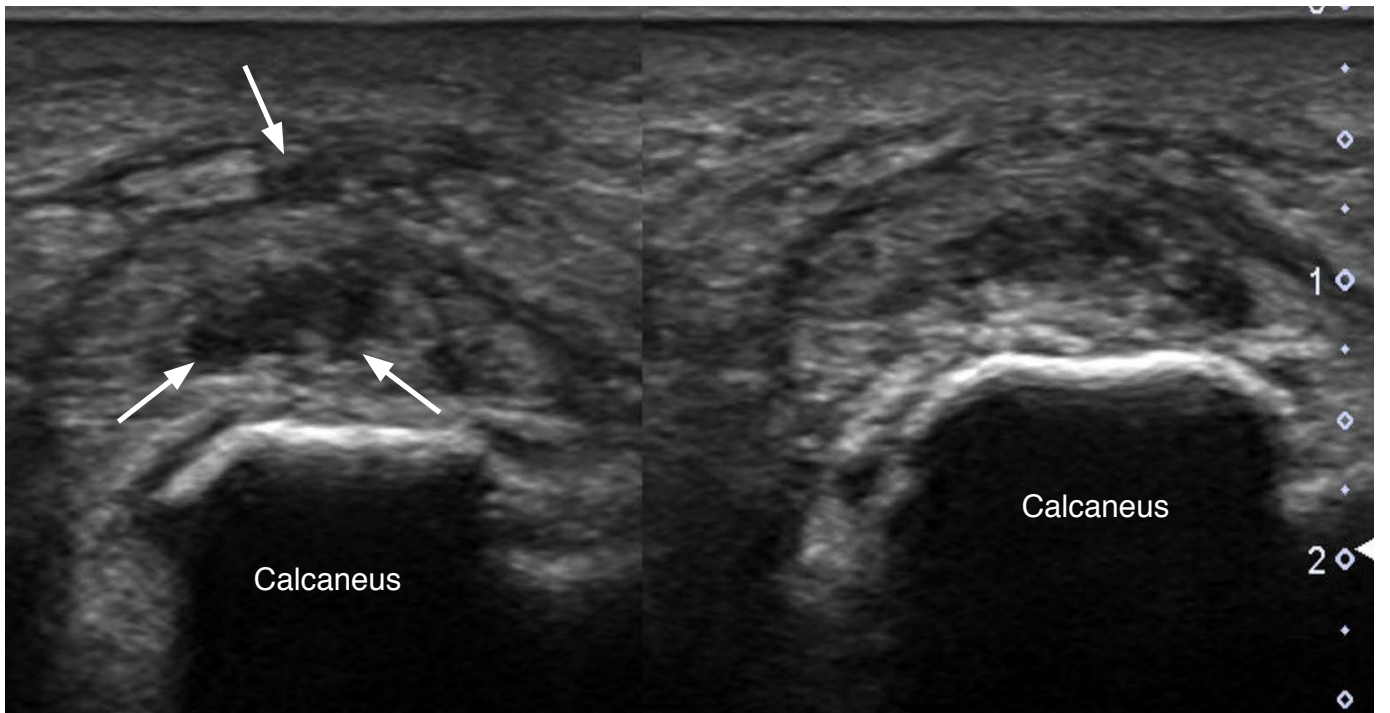

Not compressed

spectrum of adventitial bursitis and are reported to be common in rheumatoid arthritis patients [39-41]. Abnormal thickness of the uncompressed HFP $(<12 \mathrm{~mm}$ or $>28 \mathrm{~mm})$ and abnormal compressibility (compressed HFP thickness/uncompressed HFP thickness $<0.45$ or $>0.75$ ) have been suggested as US criteria for HFP abnormality in various conditions $[33,42,43]$. However, in a more recent US study, abnormal findings of the HFP were also frequently found in asymptomatic endurance runners, ranging from a focal or diffuse hypoechoic area to discrete, vertically oriented hypoechoic clefts within the HFP [33]. Abnormalities of the HFP can have more clinical importance in patients with plantar heel pain, but further studies are needed. Nevertheless, we suggest that abnormal US findings could be similarly described in radiology reports for patients with typical symptoms of HFP atrophy.

\section{Baxter Neuropathy}

Entrapment of the inferior calcaneal nerve, also known as Baxter neuropathy, is often an overlooked cause of heel pain [44]. Baxter neuropathy is frequently related to plantar fasciitis and calcaneal spurs (Fig. 8C) [45]. Nevertheless, the possibility of Baxter neuropathy should always be considered in patients who have plantar heel pain with or without plantar fasciitis.

The Baxter nerve is usually the first branch of the lateral plantar nerve and courses in a medial-to-lateral direction between the abductor hallucis muscle and quadratus plantae muscle, running anteriorly to the medial calcaneal tuberosity, to supply motor branches to the abductor digiti minimi (ADM) muscle and sensory branches to the calcaneal periosteum and the long plantar ligament [45-47]. Compression of the Baxter nerve causes burning pain
Fig. 7. A 64-year-old woman with plantar heel pain. Paired short-axis views of the plantar heel show discrete hypoechoic areas within the plantar heel fat pad overlying the plantar surface of the calcaneus. The marked hypoechoic areas (arrows) noted without compression (left-side image) were easily collapsed by minimal compression with the ultrasound transducer (right-side image).

Compressed

at the plantar medial aspect of the foot, anterior to the medial calcaneal tuberosity, and may radiate distally toward the plantar lateral foot (Fig. 8A, B) $[3,48]$. Direct compression of the Baxter nerve is not easily identified on US, but atrophy and fatty changes of the ADM muscle caused by chronic denervation are readily recognized on US [30] (Video clip 1). A comparison with the adjacent muscles or the ADM muscle on the contralateral side may aid in the determination of atrophic changes (Fig. 8D) [30].

Using either US or MRI without contrast is categorized as "usually appropriate" for Baxter neuropathy in the recently released ACR appropriateness criteria for chronic foot pain [27]. However, US has some limitations in visualizing early denervation changes of the ADM muscle or soft tissue edema around the nerve in neuropathy, which would be better demonstrated by MRI [49].

\section{Posterior Heel Pain}

\section{Achilles Tendinopathy}

The Achilles tendon is formed by the confluence of the soleus muscle with the two bellies of the gastrocnemius muscle and inserts onto the posterior surface of the calcaneus $[50,51]$. In contrast to the other tendons of the ankle encased by the synovial sheath, the Achilles tendon is enveloped with thin vascularized tissue, called the paratenon [52]. Therefore, paratenonitis can occur around the tendon instead of tenosynovitis [53]. Achilles tendinopathy can be classified by its anatomic location in relation to the calcaneus, as non-insertional tendinopathy occurring $2-6 \mathrm{~cm}$ proximal to the distal insertion on the calcaneus and insertional tendinopathy occurring near the distal insertion on the calcaneus $[50,54]$. 


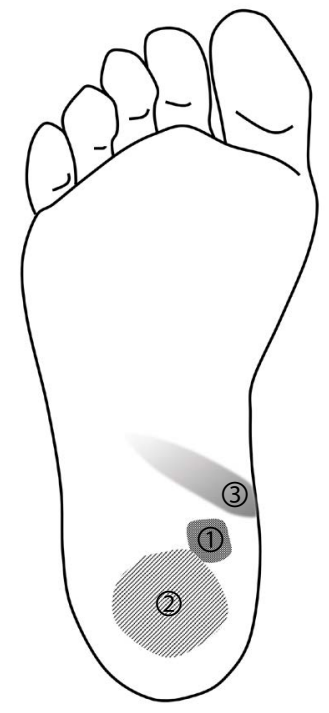

A

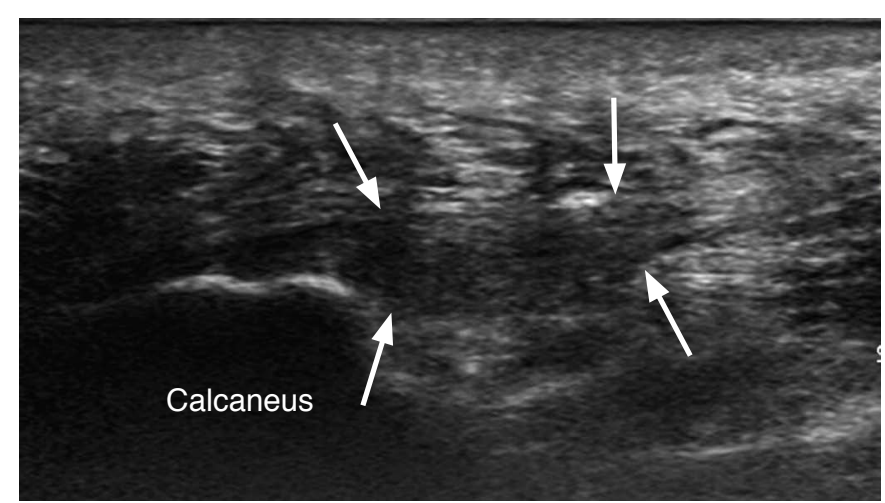

C

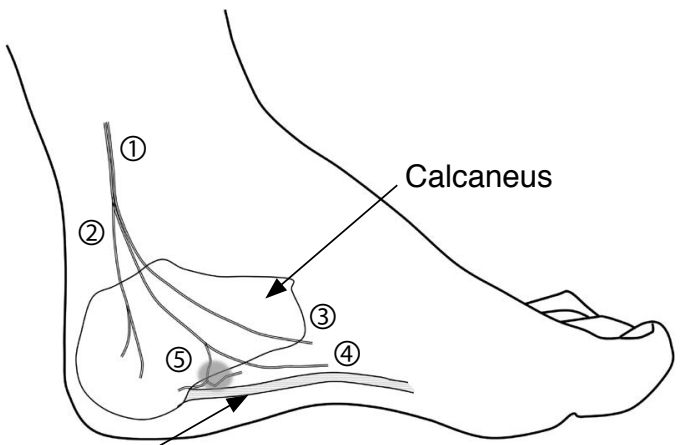

Plantar fascia

B

D
Fig. 8. A 62-year-old woman with plantar fasciitis and Baxter neuropathy, who had swelling and pain at the medial arch of the sole.

A. Anatomic location of pain in Baxter neuropathy, when compared to plantar fasciitis and heel fat pad atrophy is illustrated on the plantar surface of the foot. 1, plantar fasciitis; 2, heel fat pad atrophy; 3, Baxter neuropathy. B. The painful site of Baxter neuropathy is marked as a grey area on a schematic drawing of the posterior tibial nerve and its branches. 1, posterior tibial nerve; 2, medial calcaneal nerve; 3, medial plantar nerve; 4, lateral plantar nerve; 5, inferior calcaneal nerve (Baxter nerve). C. Long-axis view of the plantar fascia shows diffuse thickening and hypoechoic changes of the plantar fascia (arrows) near the calcaneal insertion. D. Short-axis view of the plantar midfoot level shows bright hyperechoic changes of the abductor digiti minimi (ADM) muscle when compared to the normal echo of the flexor digitorum brevis (FDB) muscle.

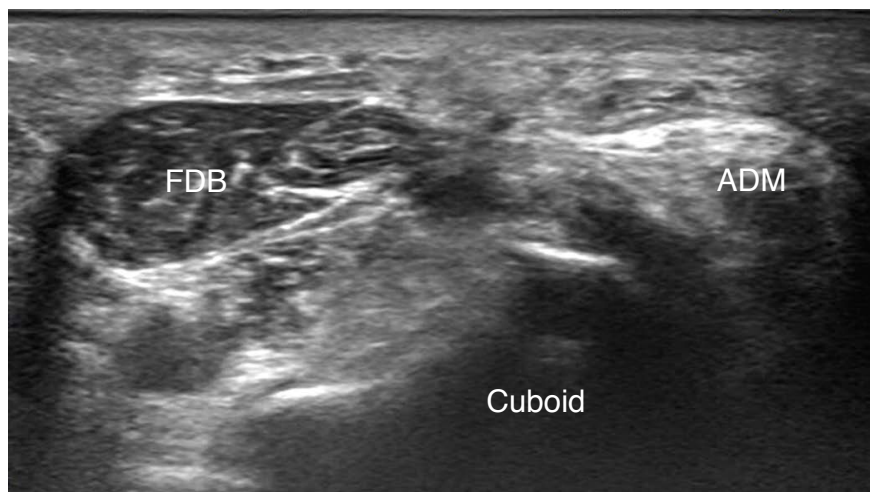

\section{Bursitis}

There are two bursae at the posterior heel. One is the retrocalcaneal bursa, which is located between the Achilles tendon and calcaneal tuberosity, and the other is the retroachilles bursa, which is located superficially over the Achilles tendon [63]. The cause of bursitis at the heel is commonly ill-fitting shoes irritating the area of Achilles tendon insertion [64]. Bursitis can be associated with Achilles tendinopathy or Haglund deformity. However, retrocalcaneal inflammation may be caused by inflammatory arthritis, such as spondyloarthritis $[65,66]$. A study suggested that bursal distension with a maximum thickness of $2 \mathrm{~mm}$ was a highly specific criterion for spondyloarthritis when compared to healthy controls or rheumatoid arthritis patients [67]. When retrocalcaneal bursitis is associated with bone erosions, inflammatory arthritis should be 


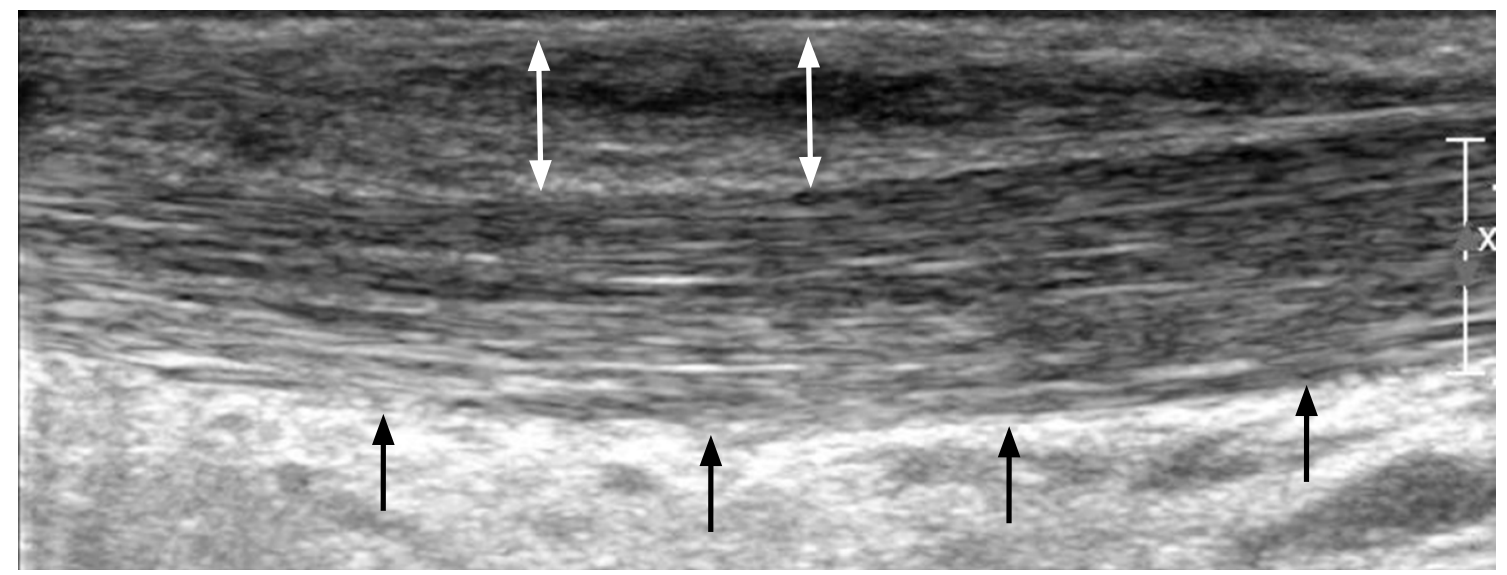

A

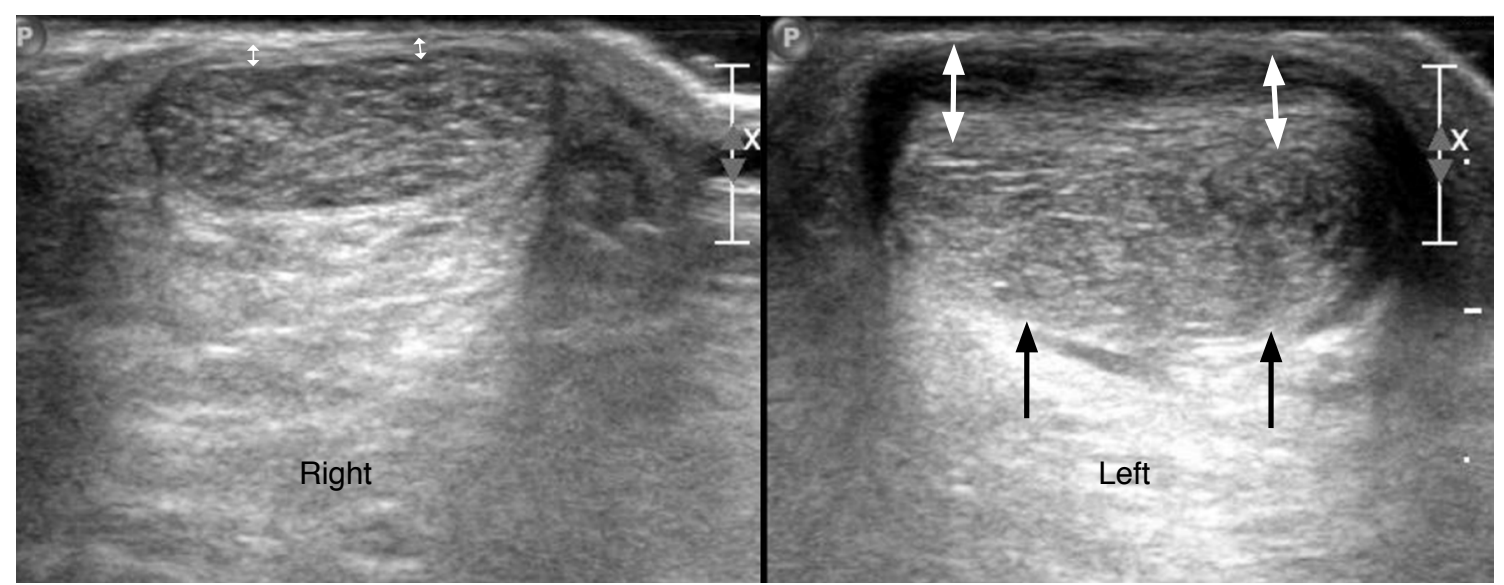

B

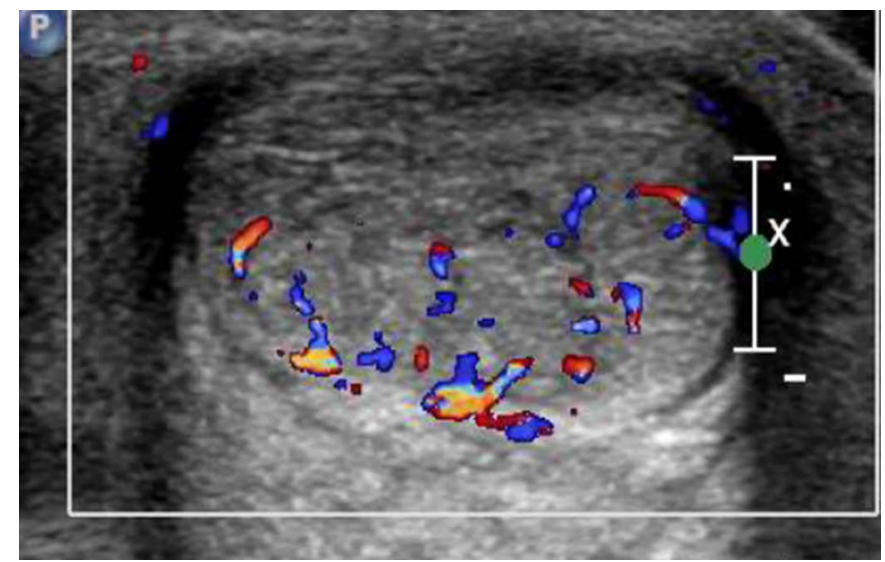

C

considered [68].

\section{Haglund Syndrome}

Haglund syndrome is a group of soft tissue and bony abnormalities caused by an abnormal protuberance of the posterosuperior border
Fig. 9. A 57-year-old woman with Achilles tendinopathy and paratenonitis.

A. Long-axis view of the left distal Achilles tendon shows attenuation of the normal fibrillar echotexture and diffuse hypoechogenicity and thickening of the Achilles tendon (black arrows). Note the irregularly shaped hypoechoic area, superficial to the Achilles tendon, suggestive of paratenonitis (double-headed white arrows). B. Short-axis view of the bilateral distal Achilles tendons shows diffuse swelling and hypoechoic changes of the left Achilles tendon (black arrows) with paratenon thickening (doubleheaded white arrows), in comparison to the right Achilles tendon (double-headed white arrows). C. Neovascularization is noted in the affected Achilles tendon. 


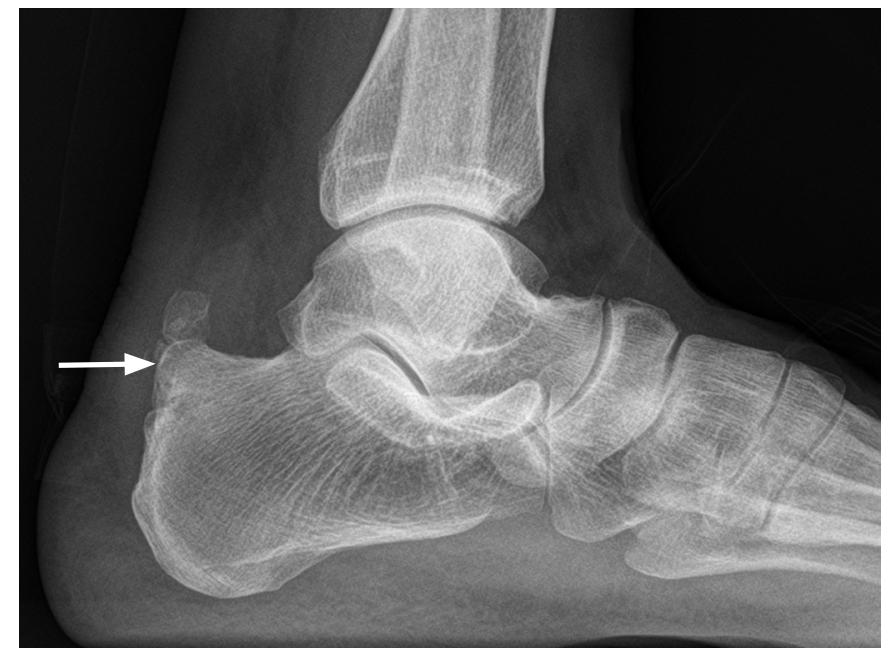

A
Fig. 10. A 67-year-old man with Haglund deformity.

A. Lateral ankle X-ray shows an abnormal bony protuberance (arrow) at the posterosuperior border of the calcaneus with multiple bone fragments. B. Long-axis view of the bilateral posterior heel shows insertional Achilles tendinopathy (black arrows) with calcifications, a bone fragment (white arrow), and retrocalcaneal bursitis (asterisk) at the affected heel. Note the normal-appearing Achilles tendon and collapsed bursa (curved arrow) on the contralateral side.

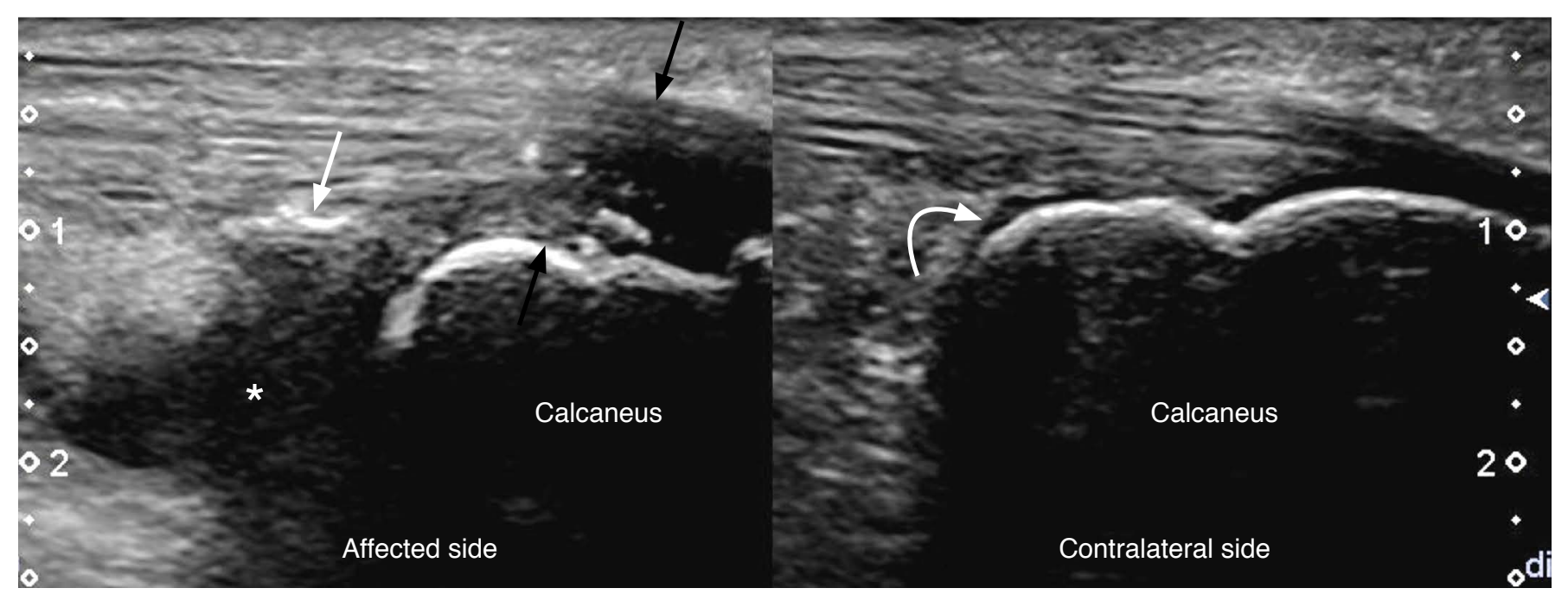

B

be made with radiographic confirmation of Haglund deformity.

\section{Medial Heel Pain}

\section{Tendinopathies}

Tendinosis, tenosynovitis, and tendon tears are common pathologic conditions that can affect the tendons at the medial ankle. These conditions have a similar US appearance to that of other tendons elsewhere in the body. Tendinosis appears as thickening of the tendon with focal or diffuse areas of hypoechogenicity and loss of normal fibrillar echotexture, often with neovascularization within the abnormal tendon on Doppler US [70]. Tenosynovitis appears as irregular thickening of the tendon sheath, usually accompanied by fluid in the tendon sheath, generating the "target sign" on shortaxis scans and the "rail-track sign" on long-axis scans [53]. One pitfall is that fluid in the tendon sheath ranging from 1 to $3 \mathrm{~mm}$ partially surrounding the medial ankle tendons can be frequently observed in the normal population [16]. A tendon tear can be observed as a hypoechoic or anechoic gap that interrupts the tendon fibers on US [53].

The tibialis posterior tendon is a fundamental stabilizer of the medial longitudinal arch of the foot, and its dysfunction is the most common cause of acquired flatfoot deformity in adults. As the pathology of the tibialis posterior tendon is thought to develop gradually by stages, initially starting with tenosynovitis and followed by partial tear and complete rupture leading to the flatfoot deformity (Fig. 11, Video clip 2), early diagnosis and treatment are crucial for preventing severe disability $[16,71,72]$. Most pathologies involving the tibialis posterior tendon are found in the watershed zone behind the medial malleolus, and less commonly at the navicular 


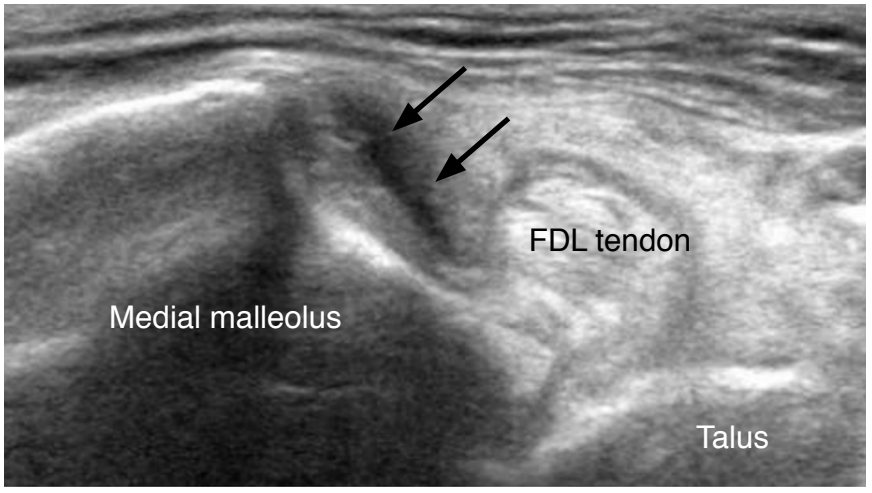

A
Fig. 11. A 75-year-old man with a nearly complete tear of the tibialis posterior tendon.

A. Short-axis view of the tibialis posterior tendon shows nearly complete discontinuity of the tendon (arrows) at the retromalleolar level. B. Extended long-axis view along the tendon course shows the gap of the torn tendon, measured as $4.8 \mathrm{~cm}$ between the calipers. FDL, flexor digitorum longus; Nav, navicular.

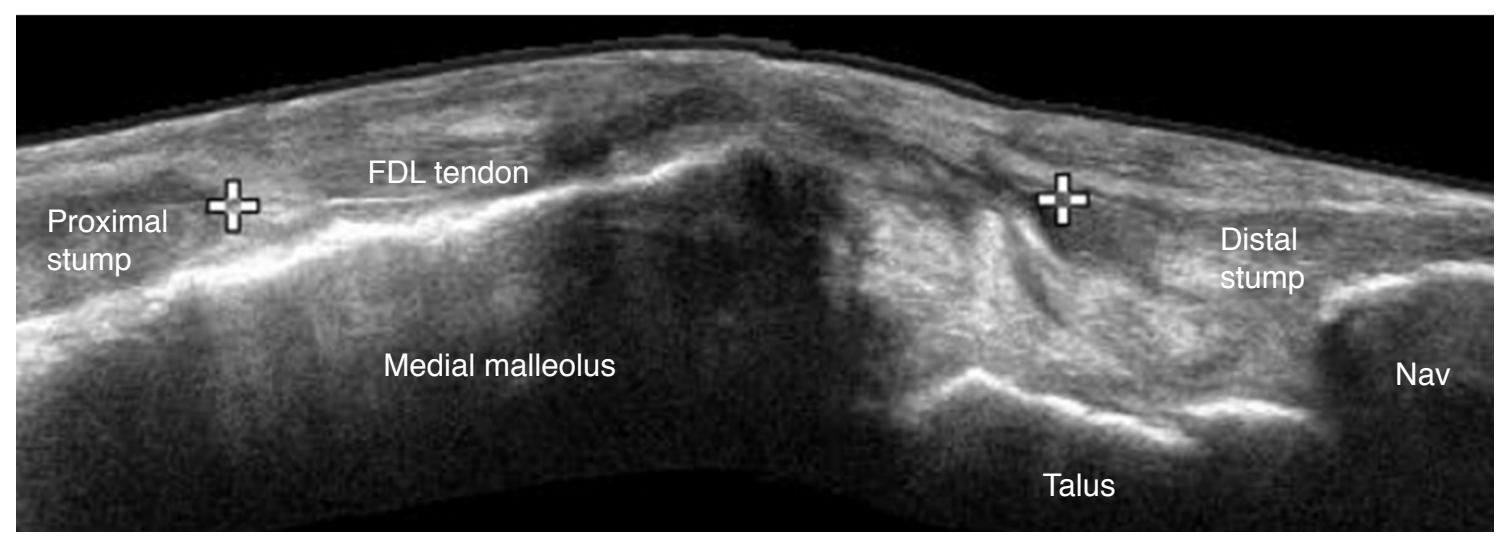

B

insertion $[16,73]$. The flexor digitorum longus tendon can be used as an internal reference when assessing the size of the tibialis posterior tendon on US. Normally, the axial diameter of the tibialis posterior tendon is approximately twice as large as that of the flexor digitorum longus tendon, which enables a rapid assessment of tendon thickening as seen in tendinosis, or thinning as can be seen in some partial tears $[16,72]$.

While pathologies of the flexor digitorum longus tendon are extremely rare, pathologies of the flexor hallucis longus tendon can be seen mostly in individuals involved in sports that require extreme plantar flexion of the ankle, such as ballet dancers and soccer players $[16,72]$. Repeated friction in the tarsal tunnel can lead to acute tenosynovitis, stenosing tenosynovitis (Fig. 12), and tendinosis of the flexor hallucis longus tendon [72]. Dynamic US with flexion and extension of the great toe can aid identifying the flexor hallucis longus tendon and reproduce triggering or snapping of the tendon in the case of stenosing tenosynovitis (Video clip 3) $[16,74]$.

\section{Tarsal Tunnel Syndrome}

The tarsal tunnel is a fibro-osseous tunnel at the medial side of the ankle beneath the flexor retinaculum, behind and inferior to the medial malleolus. The floor of the tunnel is formed by the medial wall of the distal tibia, talus, and calcaneus [75]. Entrapment of the tibial nerve or its branches within the tarsal tunnel is referred to as tarsal tunnel syndrome and is characterized by numbness and pain in the toes and sole of the foot $[30,76]$.

Both US and MRI are known to be useful for finding accessory muscles, masses, and other space-occupying lesions and determining the lesion extent and relationship to the tibial nerve and its branches $[77,78]$. US can also be used for stress assessment with the patient in the standing position, whereas MRI can better demonstrate early denervation changes in the muscle and some soft tissue masses such as lipomas [78].

Only $60 \%$ to $80 \%$ of tarsal tunnel syndrome cases are identified as having a specific cause [79]. The leading causes of spaceoccupying lesions in tarsal tunnel syndrome vary across studies, with varicose veins being the most common cause in an Italian study [78], and ganglion cysts and talocalcaneal coalition being common causes in Japanese studies $[76,80]$. Ganglion cysts within the tarsal tunnel most commonly arise from the talocalcaneal or talocrural joint, and may coexist with talocalcaneal coalition [76,81]. On US, ganglion cysts (Fig. 13, Video clip 4) appear as well-demarcated anechoic to hypoechoic masses with multiple internal septations and always without internal vascularity [30]. In patients with talocalcaneal 


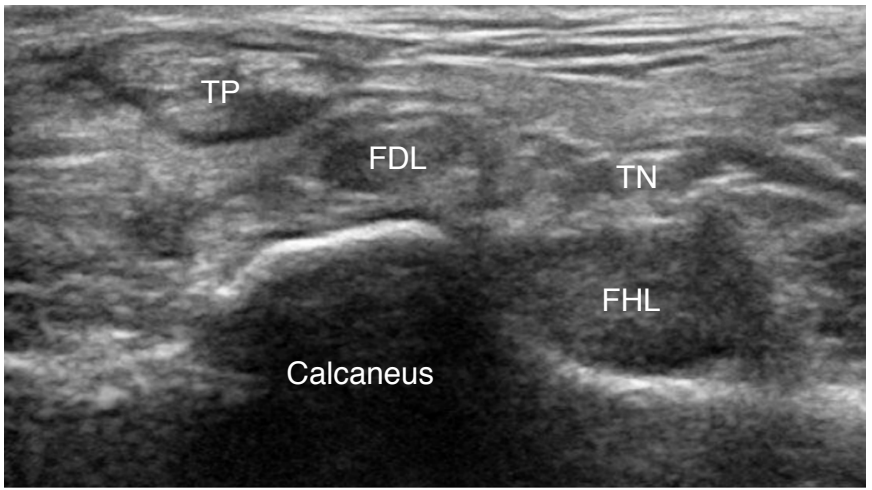

A

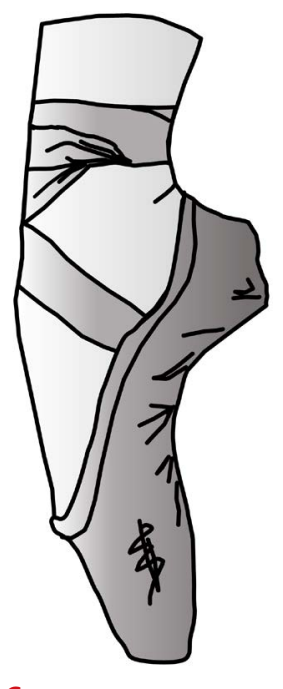
tenosynovitis, and snapping.

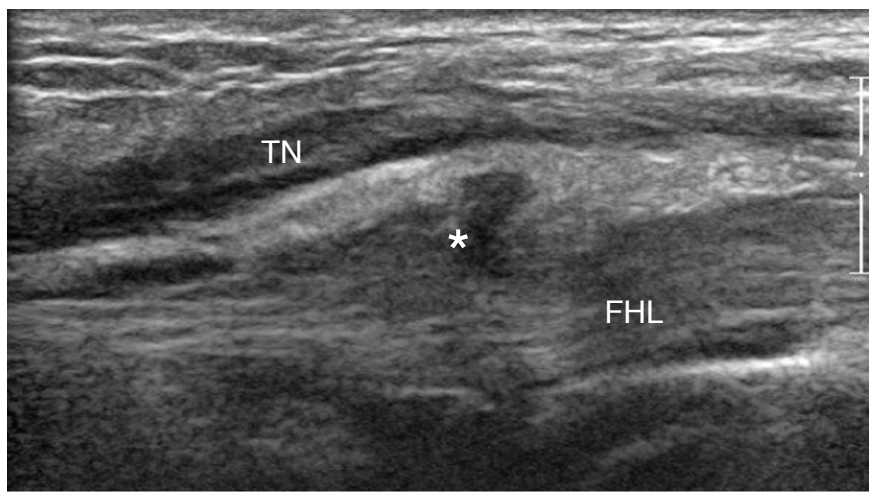

B

Fig. 12. A 12-year-old girl who was a ballet student with bilateral flexor hallucis longus tendinopathy,

A. Short-axis view of the flexor hallucis longus tendon shows marked enlargement when compared to the adjacent flexor digitorum longus (FDL) tendon. B. Long-axis view of the flexor hallucis longus (FHL) tendon shows severe thickening and decreased echogenicity of the tendon with diffuse synovial hypertrophy (asterisk) in the tendon sheath. C. Typical foot and ankle position with full plantar flexion is shown when the ballet dancer is en pointe in pointe shoes. TP, tibialis posterior tendon; TN, tibial nerve.

C

coalition, US may reveal a prominent irregular bony outline, or beakshaped appearance of the medial talus overlying the sustentaculum tali $[30,76]$. Varicose vein is a frequently underdiagnosed, but common cause of tarsal tunnel syndrome, reported to represent $13 \%$ of cases in a literature review by Lau and Daniels [79]. A varicose vein in tarsal tunnel may appear as bulbous enlargements of the venous structure on US [76]. In a study of 81 cases, 21 cases were diagnosed as tarsal tunnel syndrome by identifying varicose plantar veins in the distal tarsal tunnel measuring $>5 \mathrm{~mm}$ in diameter on US or being tortuous with signs of venous stasis in standing position [78]. Tarsal tunnel syndrome can also be caused by other etiologies, including osteophytes, hypertrophic retinaculum, tendinopathies, trauma, inflammatory arthritis, foot deformities (varus or valgus heel) $[75,76,79]$, and other space-occupying lesions, such as tumors or supernumerary muscles, especially the flexor digitorum accessorius longus muscle $[78,82]$ and accessory abductor hallucis muscle [79]. Because US has a limited window for deeper structures, radiologists should actively look for the possible causes of tarsal tunnel syndrome in suspected cases, and a comparison
Table 2. Suggested protocol to evaluate tarsal tunnel syndrome

\begin{tabular}{|c|c|}
\hline Position of patient & Checklist \\
\hline Supine with out-toeing & $\begin{array}{l}\text { Comparison of the bilateral tibial nerves, two } \\
\text { plantar nerves, and inferior calcaneal nerves } \\
\text { Screening for a static compressive lesion } \\
\text { US Tinel test } \\
\text { Comparison of bilateral foot muscle volume } \\
\text { and echogenicity }\end{array}$ \\
\hline Standing & $\begin{array}{l}\text { Screening for a dynamic compressive lesion } \\
\text { such as in the medial process of talus in valgus } \\
\text { flat foot } \\
\text { Dilatation of plantar veins in distal tarsal tunnel } \\
\text { (diameter }>5 \mathrm{~mm} \text { ) or venous stasis } \\
\text { US Tinel test }\end{array}$ \\
\hline
\end{tabular}

US, ultrasonography.

with the contralateral side is very important. A dynamic examination during the movements of the ankle and local compression by the US transducer can help to confirm the diagnosis by reproducing the patient's symptoms (US Tinel test) [30]. The suggested scanning 


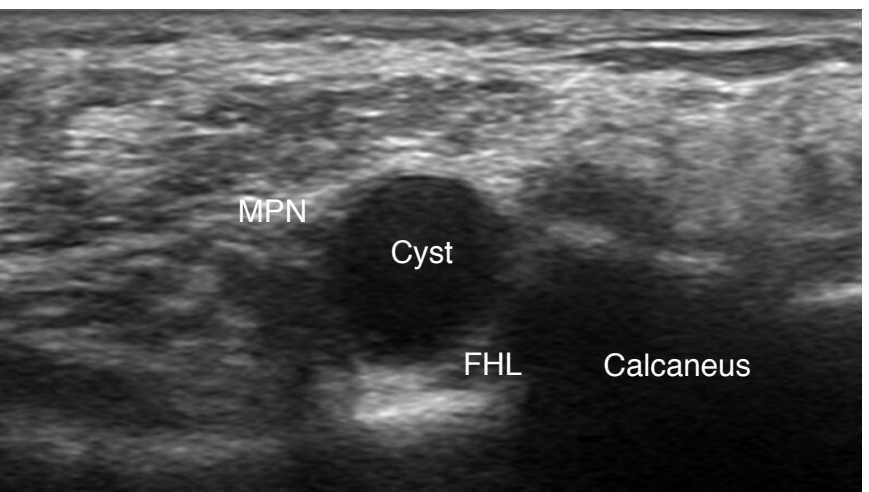

A

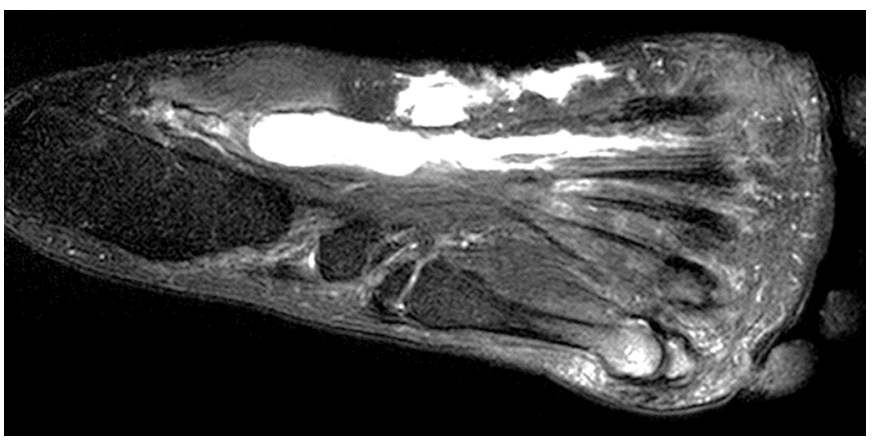

C

protocol modified from a large series of tarsal tunnel syndrome assessed with US by Fantino [78] is provided in Table 2 .

\section{Lateral Heel Pain}

\section{Peroneal Tendon Pathologies}

The peroneal tendons can develop various pathologies including tenosynovitis, tendinosis, and tendon tears. Tenosynovitis of the peroneal tendons usually appears as an irregularly thickened and hypoechoic synovial membrane with a significant amount of effusion on US. Tendinosis appears as hypoechoic thickening of the tendon without a defect [83]. Tears of the peroneal tendons are usually the longitudinal split type, whereas complete ruptures are much less common [16]. The peroneus brevis is more commonly affected by pathologies than the peroneus longus tendon because of its location between the peroneus longus tendon and fibula, being susceptible to degenerative tears $[16,83]$. On US, key findings of peroneus brevis tears are either incomplete cleft of the tendon or complete cleft with the formation of two distinct hemi-tendons, irregularities of the tendon, or signs of associated tenosynovitis (Fig. 14, Video clip 5) [83]. Tears of the peroneus longus tendon can occur in isolation or in combination with peroneus brevis tendon tears [84]. Isolated peroneus longus tears commonly occur at the level of the

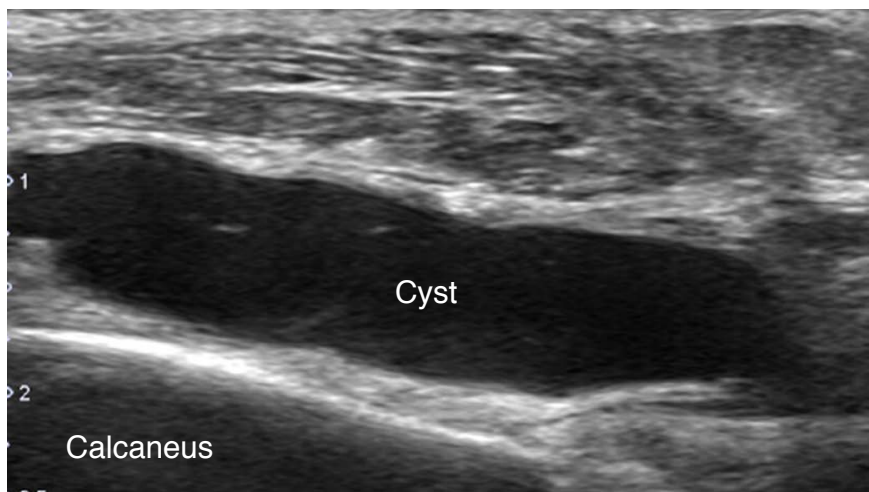

B

Fig. 13. A 60-year-old woman with an intraneural ganglion cyst at the tarsal tunnel.

Short-axis view (A) and long-axis view (B) of the right-side tarsal tunnel shows a well-defined anechoic mass inside of the tarsal tunnel, adjacent to the medial plantar nerve and superficial to the flexor hallucis longus (FHL) tendon. C. T2-weighted fat-suppressed magnetic resonance imaging reveals a cystic mass that had propagated along the course of the medial plantar nerve.

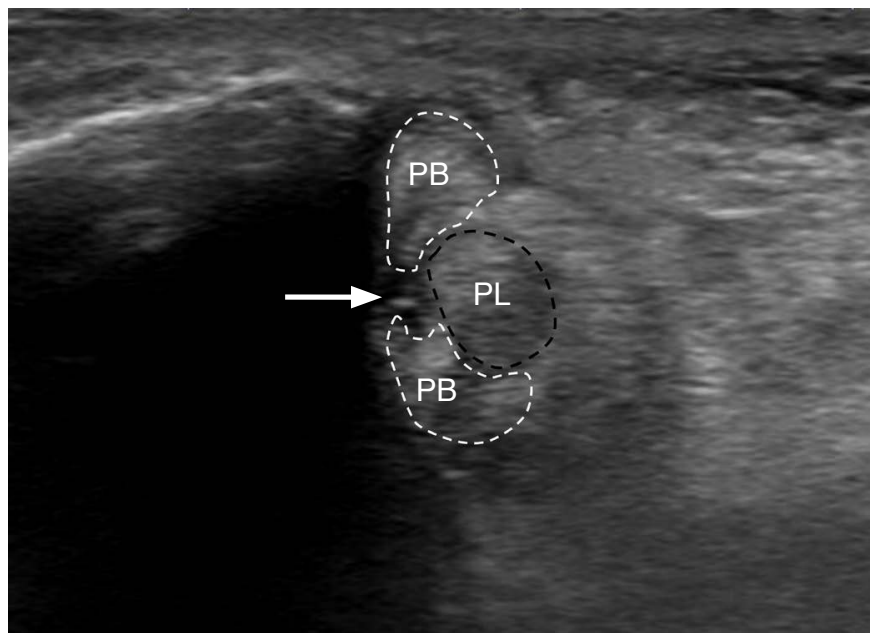

Fig. 14. A 76-year-old woman with peroneal tendinopathy and split tear of the peroneus brevis. Short-axis view of the peroneal tendons at the retromalleolar level shows enlarged peroneal tendons with a longitudinal split tear gap (arrow) at the peroneus brevis tendon, which is pushed anteriorly by the peroneus longus tendon toward the lateral malleolus. $\mathrm{PB}$, peroneus brevis tendon; $\mathrm{PL}$, peroneus longus tendon.

cuboid tunnel, whereas peroneus brevis tendon tears often occur at the retromalleolar groove [83]. 
Instability of the peroneal tendons is an uncommon phenomenon found in $0.3 \%-0.5 \%$ of cases after ankle injuries. Peroneal tendon instability includes anterior subluxation and dislocation of the peroneal tendons with associated superior peroneal retinaculum (SPR) injury, and intrasheath subluxation (Video clip 6), in which the peroneal tendons subluxate over each other with an intact SPR $[85,86]$. Due to its dynamic capability, US has shown to be a highly effective method to diagnose peroneal tendon subluxation $[87,88]$. For evaluation of peroneal tendon instability, the US transducer should be placed over the peroneus tendons in a short-axis view, at the level of the lateral malleolus. Simultaneous dorsiflexion and eversion of the foot with or without resistance applied by the examiner's free hand will reproduce the dislocation of the peroneal tendons. It is important to apply a large amount of gel to prevent the US transducer from causing excessive local pressure, which may block tendon dislocation during the dynamic study [89].

\section{Sinus Tarsi Syndrome}

Sinus tarsi syndrome is a relatively unfamiliar condition presenting with pain in the lateral hindfoot, often with increased pain on

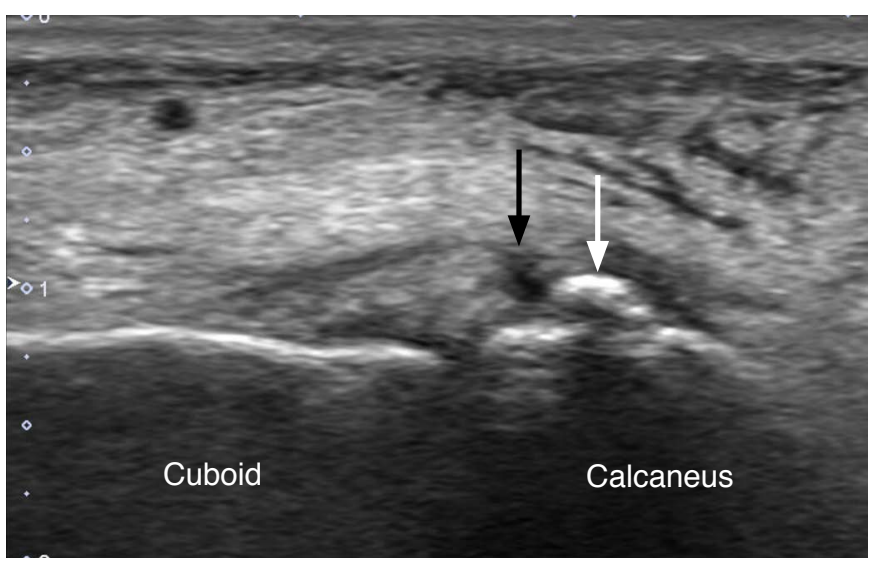

A

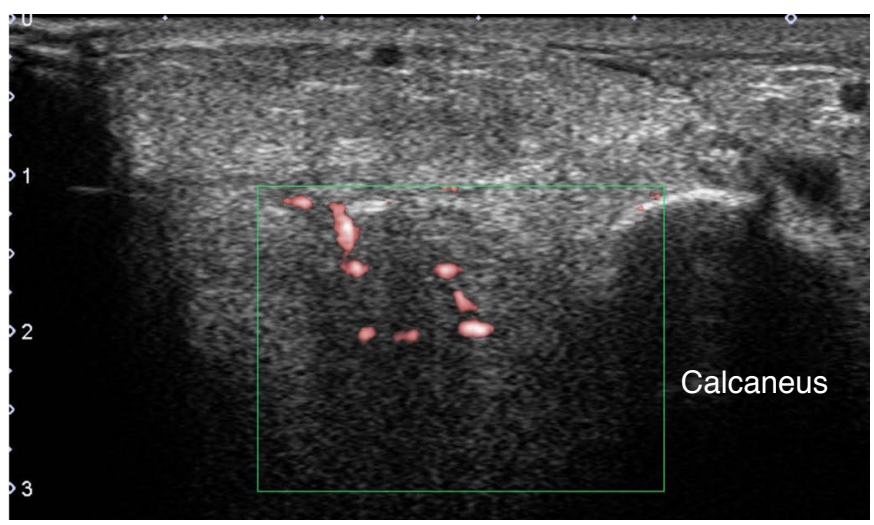

palpation over the sinus tarsi, and a subjective sensation of hindfoot instability $[1,90]$. The most common cause of sinus tarsi syndrome is single or multiple episodes of ankle sprain, causing the instability of the subtalar joint, which exerts excessive forces onto the tissues in the sinus tarsi, eventually resulting in subtalar joint synovitis with chronic inflammation and infiltration of fibrotic tissues in the sinus tarsi $[91,92]$. Other less common causes of sinus tarsi syndrome are hindfoot deformities, such as in posterior tibialis tendon injuries, and inflammatory conditions, such as rheumatoid arthritis or gout $[92,93]$. By placing the ultrasound probe at the lateral aspect of the ankle in the oblique coronal plane, the sinus tarsi can be identified as a triangular space between the anterior-superior surface of the calcaneus and the talar neck. The US findings of sinus tarsi syndrome are an abnormally hypoechoic appearance in the sinus tarsi, hyperemia on Doppler imaging (Fig. 15), and narrowing or obliteration of the sinus tarsi in advanced cases [94].

\section{Sural Neuropathy}

The sural nerve is a small sensory nerve located in the subcutaneous tissue of the calf, supplying the lateral inferior third of the leg,

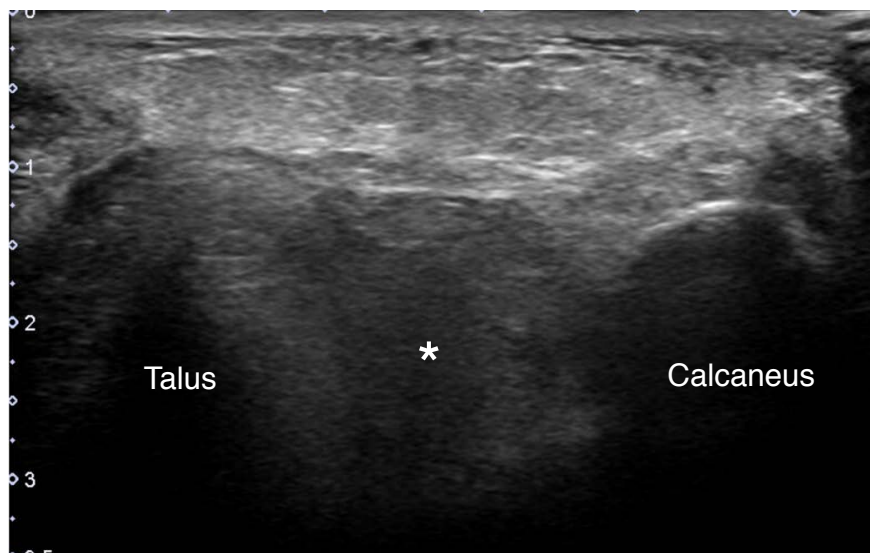

B

Fig. 15. A 46-year-old woman with repeated ankle sprain and sinus tarsi syndrome.

A. Long-axis view of the calcaneocuboidal joint at the lateral heel shows a chronic avulsion fracture fragment (white arrow) at the calcaneus and a focal discontinuity (black arrow) of the calcaneocuboidal ligament. B. Oblique coronal scanning over the sinus tarsi shows hypoechoic changes in the sinus tarsi (asterisk), which is a finding of sinus tarsi syndrome. C. Hyperemia was noted in the sinus tarsi on Doppler ultrasonography. 
lateral ankle, and foot. It runs close to the small saphenous vein and the lateral margin of the Achilles tendon at the distal calf, and around the lateral malleolus at ankle level, and then follows the peroneal tendons (Fig. 16A) [95]. The superficial location of the sural nerve and its close relationship with the Achilles tendon and small saphenous vein render it prone to either direct trauma or postsurgical trauma during surgical procedures on the gastrocnemius muscle, Achilles tendon, and varicose veins $[96,97]$.

US is the most preferred imaging modality for evaluation of the sural nerve, because of its high resolution and easy accessibility

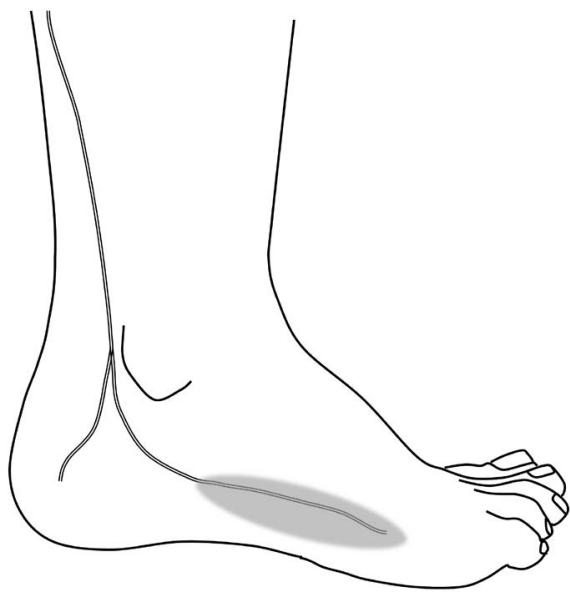

A
Fig. 16. A 47-year-old man with lateral foot pain caused by sural neuropathy. He had an ankle inversion injury several years ago.

A. A schematic illustration of the course of sural nerve at lateral heel and the patient's symptomatic area is shown as a grey area. B. Paired short-axis view of the bilateral sural nerve at the level of the peroneal tubercle shows hypoechoic thickening of the right-side sural nerve (black arrow), when compared to the normal left-side sural nerve (white arrow). C. Long-axis view of the sural nerve shows fusiform thickening and hypoechoic changes of the sural nerve (black arrows).

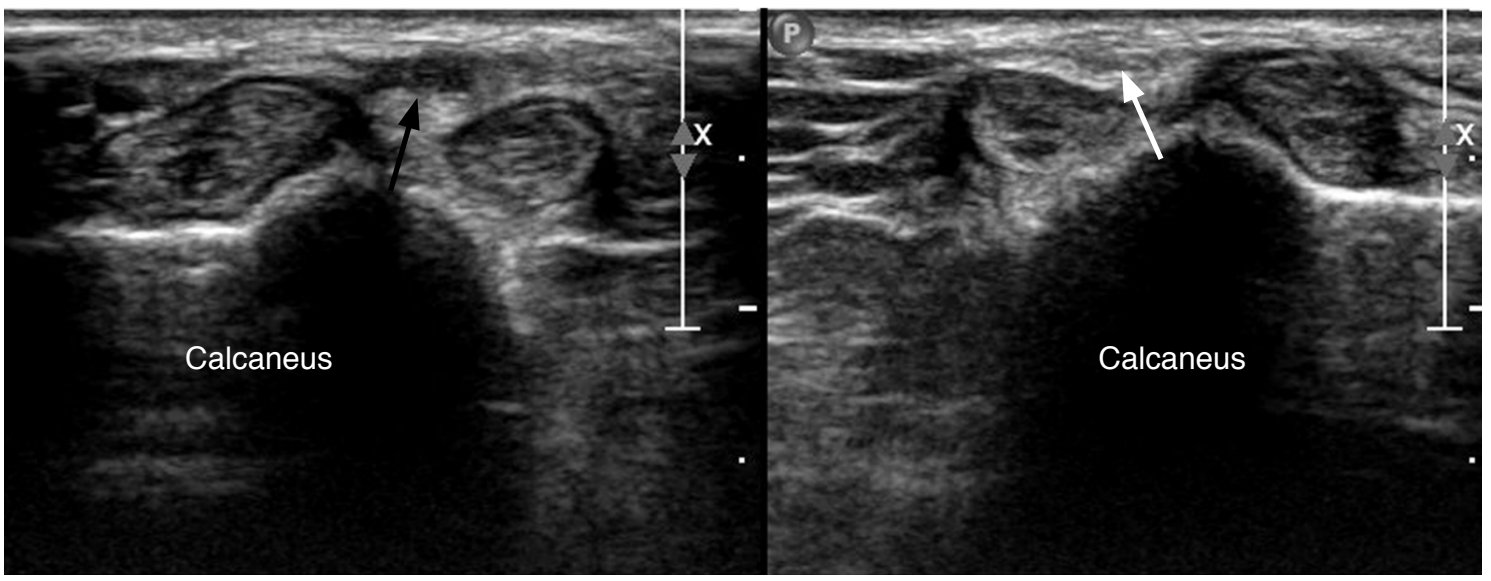

B

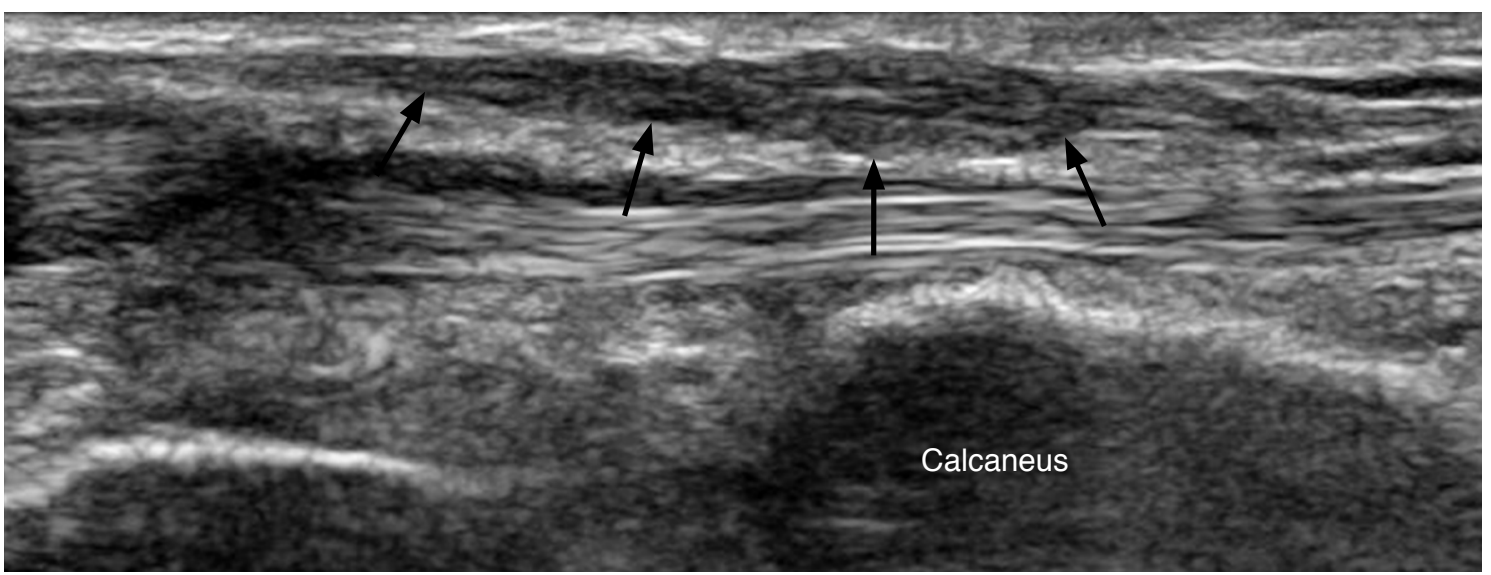

C 


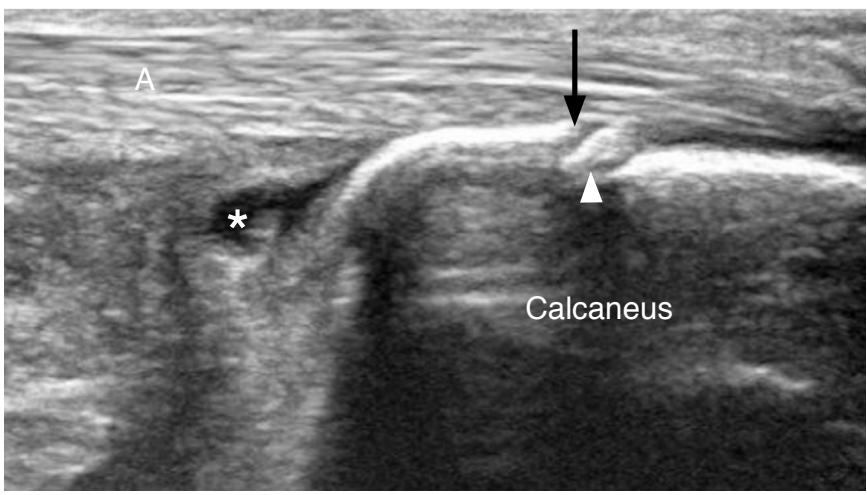

A

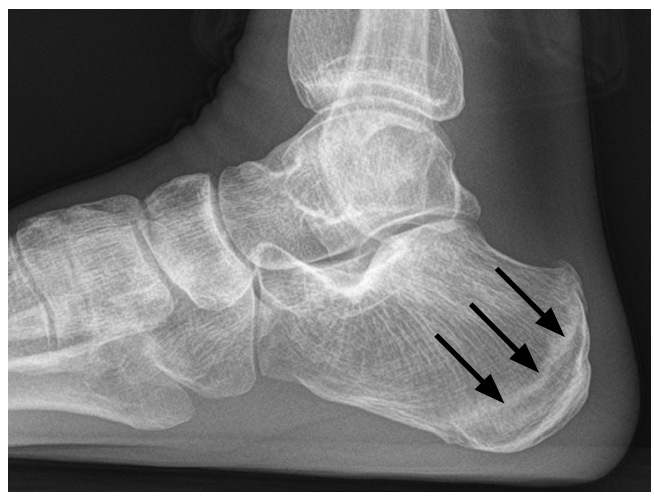

B

Fig. 17. A 46-year-old woman with calcaneal stress fracture.

A. Long-axis view of the calcaneal tuberosity at the posterior heel reveals cortical step-off (black arrow) with a small fracture fragment (white arrowhead). Note the small amount of effusion present in the retrocalcaneal bursa (asterisk). B. Lateral ankle X-ray taken after 3 weeks demonstrated a radio-opaque fracture line (black arrows) at the calcaneal tuberosity, which was not visible on an initial X-ray (not shown in the figure). A, Achilles tendon.

$[95,98,99]$. The US findings of posttraumatic sural nerve may vary from mild thickening of the nerve (Fig. 16B, C) to complete discontinuity of the nerve fascicles according to the severity of injury $[95,98]$. Rbia et al. [99] reported that the best cut-off value of the sural nerve cross-sectional area was $8.3 \mathrm{~mm}^{2}$ to diagnose sural neuropathy after ankle surgery, with sensitivity and specificity of $57 \%$ and $92 \%$, respectively. Other reported findings of nerve pathology are increased or decreased echogenicity, changes in fascicle morphology, and increased endoneurial/perineurial blood flow [99]. A comparison to the contralateral side and provocation of the symptom by applying local pressure to the pathologic site by the US transducer can increase the diagnostic confidence [95].

\section{Deep and Vague Pain}

\section{Calcaneal Stress Fracture}

The calcaneus is one of the most common locations of stress fractures in the foot, second only to the metatarsals [3]. Although US is not routinely used as the first-line imaging modality in the diagnosis of bone disorders, a US examination can lead to suspicion of calcaneal stress fracture (Fig. 17). US findings that warrant suspicion of a stress fracture are irregularity of the calcaneal cortex with an adjacent hypoechoic line, which represents edema and thickening of the periosteum, and increased vascularity on color Doppler imaging $[26,100]$. The cortical discontinuity is not always visible even in the presence of a fracture, because the calcaneal stress fracture may only involve the internal trabecular bone, not affecting the outer cortex of the calcaneus [100].

\section{Conclusion}

To use US as a problem-solving tool to evaluate heel pain, radiologists should communicate with patients about the detailed location and characteristics of the pain and should correlate that information with the US findings. Moreover, knowing what to look for and being familiar with pathologic US findings in patients who have typical symptoms will help radiologists to perform accurate and effective US examinations.

ORCID: Yong Hee Kim: https://orcid.org/0000-0003-0033-787X; Jee Won Chai: https://orcid.org/0000-0003-1630-1863; Dong Hyun Kim: https://orcid.org/00000002-3871-7002; Hyo Jin Kim: https://orcid.org/0000-0002-0549-5722; Jiwoon Seo: https://orcid.org/0000-0002-1810-2342

\section{Author Contributions}

Conceptualization: Kim YH, Chai JW. Data acquisition: Kim YH, Chai JW, Kim DH, Kim HJ. Data analysis or interpretation: Kim YH, Chai JW, Seo J. Drafting of the manuscript: Kim YH, Chai JW, Seo J. Critical revision of the manuscript: Kim YH, Chai JW, Kim DH, Kim HJ. Approval of the final version of the manuscript: all authors.

\section{Conflict of Interest}

No potential conflict of interest relevant to this article was reported.

\section{Supplementary Materials}

Video clip 1. A 62-year-old woman with plantar fasciitis and Baxter neuropathy. Short-axis view of the plantar foot scanning from the proximal to distal direction is shown. Diffuse hyperechoic changes of 
the abductor digiti minimi muscle were apparent when compared to the normal flexor digitorum brevis muscle (https://doi.org/10.14366/ usg.21069.v001).

Video clip 2. A 75-year-old man with a nearly complete tear of the tibialis posterior tendon. Short-axis view of the tibialis posterior tendon scanning from the proximal to distal direction is shown. The proximal tendon is enlarged with a proximally retracted stump, followed by a nearly complete discontinuity of the tendon at the retromalleolar level. The residual stump at the distal tendon shows diffuse enlargement and hypoechoic changes, suggesting severe tendinopathy. Note the type 2 accessory navicular at the distal tendon attachment site. TP, tibialis posterior; FDL, flexor digitorum longus; Acc. Nav., accessory navicular (https://doi.org/10.14366/ usg.21069.v002).

Video clip 3. A 12-year-old girl with bilateral flexor hallucis longus tendinopathy and tenosynovitis with snapping. Long-axis view of the flexor hallucis longus tendon shows severe thickening and decreased echogenicity of the tendon with diffuse synovial hypertrophy in the tendon sheath. Visible and audible snapping of the tendon was observed during flexion and extension of the great toe (https://doi. org/10.14366/usg.21069.v003).

Video clip 4. A 60-year-old woman with surgically confirmed intraneural ganglion cyst at the tarsal tunnel. Short-axis view of the right-side tarsal tunnel scanning from the proximal to distal direction is shown. A well-defined lobulated anechoic cystic mass is located inside of the tarsal tunnel, anterior to the posterior tibial vessels, and superficial to the flexor hallucis longus tendon (https:// doi.org/10.14366/usg.21069.v004).

Video clip 5. A 76-year-old woman with peroneal tendinopathy and split tear of the peroneus brevis. Short-axis view of the peroneal tendons scanning from the proximal to distal direction is shown. Ultrasonography at the retromalleolar level shows enlarged peroneal tendons with a localized longitudinal split tear at the peroneus brevis tendon, which is pushed anteriorly by the peroneus longus tendon toward the lateral malleolus (https://doi.org/10.14366/ usg.21069.v005).

Video clip 6. A 27-year-old man with peroneal tendon intrasheath subluxation. Short-axis view of the peroneal tendons scanning obliquely from the lateral malleolus to the calcaneus, perpendicular to the peroneal tendons is shown. Ultrasonography shows the peroneus brevis and peroneus longus tendons switching their positions with ankle dorsiflexion and eversion (https://doi. org/10.14366/usg.21069.v006).

\section{References}

1. Tu P. Heel pain: diagnosis and management. Am Fam Physician 2018;97:86-93.

2. Thomas JL, Christensen JC, Kravitz SR, Mendicino RW, Schuberth $J M$, Vanore JV, et al. The diagnosis and treatment of heel pain: a clinical practice guideline-revision 2010. J Foot Ankle Surg 2010;49(3 Suppl):S1-S19.

3. Lareau CR, Sawyer GA, Wang JH, DiGiovanni CW. Plantar and medial heel pain: diagnosis and management. J Am Acad Orthop Surg 2014;22:372-380.

4. Rio E, Mayes $S$, Cook J. Heel pain: a practical approach. Aust Fam Physician 2015;44:96-101.

5. Gibbon WW, Long G. Ultrasound of the plantar aponeurosis (fascia). Skeletal Radiol 1999;28:21-26.

6. Sabir N, Demirlenk S, Yagci B, Karabulut N, Cubukcu S. Clinical utility of sonography in diagnosing plantar fasciitis. J Ultrasound Med 2005;24:1041-1048.

7. Bianchi S, Martinoli C, Gaignot C, De Gautard R, Meyer JM. Ultrasound of the ankle: anatomy of the tendons, bursae, and ligaments. Semin Musculoskelet Radiol 2005;9:243-259.

8. van Holesbeeck MT, Introcaso JH. Musculoskeletal ultrasound. 3rd ed. New Delhi: Jaypee Brothers Medical Publishers, 2016.

9. Theodorou DJ, Theodorou SJ, Kakitsubata Y, Lektrakul N, Gold GE, Roger $B$, et al. Plantar fasciitis and fascial rupture: MR imaging findings in 26 patients supplemented with anatomic data in cadavers. Radiographics 2000;20 Spec No:S181-S197.

10. Stecco C, Corradin M, Macchi V, Morra A, Porzionato A, Biz C, et al. Plantar fascia anatomy and its relationship with Achilles tendon and paratenon. J Anat 2013;223:665-676.

11. Sichting F, Holowka NB, Ebrecht F, Lieberman DE. Evolutionary anatomy of the plantar aponeurosis in primates, including humans. J Anat 2020;237:85-104.

12. Riddle DL, Schappert SM. Volume of ambulatory care visits and patterns of care for patients diagnosed with plantar fasciitis: a national study of medical doctors. Foot Ankle Int 2004;25:303-310.

13. Lemont $\mathrm{H}$, Ammirati KM, Usen N. Plantar fasciitis: a degenerative process (fasciosis) without inflammation. J Am Podiatr Med Assoc 2003;93:234-237.

14. leong E, Afolayan J, Carne A, Solan M. Ultrasound scanning for recalcitrant plantar fasciopathy: basis of a new classification. Skeletal Radiol 2013;42:393-398.

15. Filippini C, Teh J. Ultrasound features of sole of foot pathology: a review. J Ultrason 2019;19:145-151.

16. Fessell DP, Jacobson JA. Ultrasound of the hindfoot and midfoot. Radiol Clin North Am 2008;46:1027-1043.

17. Cardinal E, Chhem RK, Beauregard CG, Aubin B, Pelletier M. Plantar 
fasciitis: sonographic evaluation. Radiology 1996;201:257-259.

18. Granado MJ, Lohman EB 3rd, Gordon KE, Daher NS. Metatarsophalangeal joint extension changes ultrasound measurements for plantar fascia thickness. J Foot Ankle Res 2018;11:20.

19. Wall JR, Harkness MA, Crawford A. Ultrasound diagnosis of plantar fasciitis. Foot Ankle 1993;14:465-470.

20. McMillan AM, Landorf KB, Gregg JM, De Luca J, Cotchett MP, Menz HB. Hyperemia in plantar fasciitis determined by power Doppler ultrasound. J Orthop Sports Phys Ther 2013;43:875-880.

21. Tas $S$, Bek N, Ruhi Onur M, Korkusuz F. Effects of body mass index on mechanical properties of the plantar fascia and heel pad in asymptomatic participants. Foot Ankle Int 2017;38:779-784.

22. Ozdemir H, Yilmaz E, Murat A, Karakurt L, Poyraz AK, Ogur E. Sonographic evaluation of plantar fasciitis and relation to body mass index. Eur J Radiol 2005;54:443-447.

23. Walther M, Radke S, Kirschner S, Ettl V, Gohlke F. Power Doppler findings in plantar fasciitis. Ultrasound Med Biol 2004;30:435-440.

24. Griffith JF, Wong TY, Wong SM, Wong MW, Metreweli C. Sonography of plantar fibromatosis. AJR Am J Roentgenol 2002;179:11671172.

25. Cohen BE, Murthy NS, McKenzie GA. Ultrasonography of plantar fibromatosis: updated case series, review of the literature, and a novel descriptive appearance termed the "comb sign". J Ultrasound Med 2018;37:2725-2731.

26. Hoffman DF, Grothe HL, Bianchi S. Sonographic evaluation of hindfoot disorders. J Ultrasound 2014;17:141-150.

27. Expert Panel on Musculoskeletal Imaging; Tafur M, Bencardino JT, Roberts CC, Appel M, Bell AM, et al. ACR appropriateness criteria(R) chronic foot pain. J Am Coll Radiol 2020;17(11S):S391-S402.

28. Lee HS, Choi YR, Kim SW, Lee JY, Seo JH, Jeong JJ. Risk factors affecting chronic rupture of the plantar fascia. Foot Ankle Int 2014:35:258-263.

29. Debus F, Eschbach D, Ruchholtz $S$, Peterlein CD. Rupture of plantar fascia: current standard of therapy: a systematic literature review. Foot Ankle Surg 2020;26:358-362.

30. Hoffman D, Bianchi S. Sonographic evaluation of plantar hindfoot and midfoot pain. J Ultrasound Med 2013;32:1271-1284.

31. McNally EG, Shetty S. Plantar fascia: imaging diagnosis and guided treatment. Semin Musculoskelet Radiol 2010;14:334-343.

32. Kho JSB, Almeer G, McGarry S, James SL, Botchu R. Technical report: dynamic assessment of plantar fasciitis and plantar fascia tears utilising dorsiflexion of the great toe. J Ultrasound 2020;23:397400.

33. Hall MM, Finnoff JT, Sayeed YA, Smith J. Sonographic Evaluation of the Plantar Heel in asymptomatic endurance runners. J Ultrasound Med 2015;34:1861-1871.

34. Yi TI, Lee GE, Seo IS, Huh WS, Yoon TH, Kim BR. Clinical characteristics of the causes of plantar heel pain. Ann Rehabil Med
2011;35:507-513.

35. Chae YH, Kim JS, Kang Y, Kim HY, Yi TI. Clinical and biomechanical effects of low-dye taping and figure-8 modification of lowdye taping in patients with heel pad atrophy. Ann Rehabil Med 2018:42:222-228.

36. Saad A, Kho J, Almeer G, Azzopardi C, Botchu R. Lesions of the heel fat pad. Br J Radiol 2021;94:20200648.

37. Falsetti P, Conticini E, Baldi C, Acciai C, D'Alessandro R, Bardelli M, et al. Observations about subcalcaneal adventitial bursitis (heel fat pad inflammatory lesion) in rheumatoid arthritis. Comment on the article of Suzuki and Shirai. Reumatismo 2020;72:182-183.

38. Lin CY, Wu CH, Ozcakar L. Restoration of heel pad elasticity in heel pad syndrome evaluated by shear wave elastography. Am J Phys Med Rehabil 2017;96:e96.

39. Falsetti P, Frediani B, Acciai C, Baldi F, Filippou G, Marcolongo $R$. Heel fat pad involvement in rheumatoid arthritis and in spondyloarthropathies: an ultrasonographic study. Scand J Rheumatol 2004;33:327-331.

40. Falsetti P, Frediani B, Acciai C, Baldi F, Filippou G, Galeazzi M, et al. Ultrasonography and magnetic resonance imaging of heel fat pad inflammatory-oedematous lesions in rheumatoid arthritis. Scand J Rheumatol 2006;35:454-458.

41. Suzuki T, Shirai H. Subcalcaneal bursitis as the initial manifestation of rheumatoid arthritis: ultrasonographic observation of two cases. Reumatismo 2020;71:230-234.

42. Lopez-Lopez D, Becerro-de-Bengoa-Vallejo R, Losa-Iglesias ME, Soriano-Medrano A, Palomo-Lopez P, Morales-Ponce A, et al. Relationship between decreased subcalcaneal fat pad thickness and plantar heel pain: a case control study. Pain Physician 2019:22:109-116.

43. Uzel M, Cetinus E, Bilgic E, Ekerbicer H, Karaoguz A. Comparison of ultrasonography and radiography in assessment of the heel pad compressibility index of patients with plantar heel pain syndrome: measurement of the fat pad in plantar heel pain syndrome. Joint Bone Spine 2006;73:196-199.

44. Baxter DE, Pfeffer GB, Thigpen M. Chronic heel pain: treatment rationale. Orthop Clin North Am 1989;20:563-569.

45. Recht MP, Grooff P, Ilaslan H, Recht HS, Sferra J, Donley BG. Selective atrophy of the abductor digiti quinti: an MRI study. AJR Am J Roentgenol 2007;189:W123-W127.

46. Louisia S, Masquelet AC. The medial and inferior calcaneal nerves: an anatomic study. Surg Radiol Anat 1999;21:169-173.

47. del Sol M, Olave E, Gabrielli C, Mandiola E, Prates JC. Innervation of the abductor digiti minimi muscle of the human foot: anatomical basis of the entrapment of the abductor digiti minimi nerve. Surg Radiol Anat 2002;24:18-22.

48. Alshami AM, Souvlis T, Coppieters MW. A review of plantar heel pain of neural origin: differential diagnosis and management. Man Ther 2008;13:103-111. 
49. Donovan A, Rosenberg ZS, Cavalcanti CF. MR imaging of entrapment neuropathies of the lower extremity. Part 2. The knee, leg, ankle, and foot. Radiographics 2010;30:1001-1019.

50. Li HY, Hua YH. Achilles tendinopathy: current concepts about the basic science and clinical treatments. Biomed Res Int 2016;2016:6492597.

51. Maffulli N, Longo UG, Kadakia A, Spiezia F. Achilles tendinopathy. Foot Ankle Surg 2020;26:240-249.

52. Maffulli N, Florio A, Osti L, Del Buono A. Achilles tendinopathy. JBJS Rev 2014;2:e5.

53. Park JW, Lee SJ, Choo HJ, Kim SK, Gwak HC, Lee SM. Ultrasonography of the ankle joint. Ultrasonography 2017;36:321335.

54. Edama M, Kubo M, Onishi H, Takabayashi T, Yokoyama E, Inai T, et al. Structure of the Achilles tendon at the insertion on the calcaneal tuberosity. J Anat 2016;229:610-614.

55. Fornage BD. Achilles tendon: US examination. Radiology 1986;159:759-764.

56. Bleakney RR, White LM. Imaging of the Achilles tendon. Foot Ankle Clin 2005:10:239-254.

57. Wongsithichai P, Chang KV. Paratenonitis. J Med Ultrasound 2014;22:55-56.

58. Stecco A, Busoni F, Stecco C, Mattioli-Belmonte M, Soldani P, Condino $S$, et al. Comparative ultrasonographic evaluation of the Achilles paratenon in symptomatic and asymptomatic subjects: an imaging study. Surg Radiol Anat 2015;37:281-285.

59. Zanetti $M$, Metzdorf $A$, Kundert HP, Zollinger $H$, Vienne $P$, Seifert $B$, et al. Achilles tendons: clinical relevance of neovascularization diagnosed with power Doppler US. Radiology 2003;227:556-560.

60. Ohberg L, Lorentzon R, Alfredson H. Neovascularisation in Achilles tendons with painful tendinosis but not in normal tendons: an ultrasonographic investigation. Knee Surg Sports Traumatol Arthrosc 2001;9:233-238.

61. Gatz M, Bode D, Betsch M, Quack V, Tingart M, Kuhl C, et al. Multimodal ultrasound versus MRI for the diagnosis and monitoring of Achilles tendinopathy: a prospective longitudinal sudy. Orthop J Sports Med 2021;9:23259671211006826.

62. Khan KM, Forster BB, Robinson J, Cheong Y, Louis L, Maclean L, et al. Are ultrasound and magnetic resonance imaging of value in assessment of Achilles tendon disorders? A two year prospective study. Br J Sports Med 2003;37:149-153.

63. Precerutti M, Bonardi M, Ferrozzi G, Draghi F. Sonographic anatomy of the ankle. J Ultrasound 2014;17:79-87.

64. Aldridge T. Diagnosing heel pain in adults. Am Fam Physician 2004;70:332-338.

65. Balint PV, Sturrock RD. Inflamed retrocalcaneal bursa and Achilles tendonitis in psoriatic arthritis demonstrated by ultrasonography. Ann Rheum Dis 2000:59:931-933.

66. Olivieri I, Barozzi L, Padula A, De Matteis M, Pierro A, Cantini F, et al. Retrocalcaneal bursitis in spondyloarthropathy: assessment by ultrasonography and magnetic resonance imaging. J Rheumatol 1998;25:1352-1357.

67. Falcao S, de Miguel E, Castillo-Gallego C, Peiteado D, Branco J, Martin Mola E. Achilles enthesis ultrasound: the importance of the bursa in spondyloarthritis. Clin Exp Rheumatol 2013;31:422-427.

68. Chang CD, Wu JS. MR imaging findings in heel pain. Magn Reson Imaging Clin N Am 2017;25:79-93.

69. Sofka CM, Adler RS, Positano R, Pavlov H, Luchs JS. Haglund's syndrome: diagnosis and treatment using sonography. HSS J 2006;2:27-29.

70. Robinson P. Sonography of common tendon injuries. AJR Am J Roentgenol 2009;193:607-618.

71. Kohls-Gatzoulis J, Angel JC, Singh D, Haddad F, Livingstone J, Berry G. Tibialis posterior dysfunction: a common and treatable cause of adult acquired flatfoot. BMJ 2004;329:1328-1333.

72. Khoury V, Guillin R, Dhanju J, Cardinal E. Ultrasound of ankle and foot: overuse and sports injuries. Semin Musculoskelet Radiol 2007:11:149-161.

73. Petersen W, Hohmann G, Stein V, Tillmann B. The blood supply of the posterior tibial tendon. J Bone Joint Surg Br 2002;84:141-144.

74. Martinez-Salazar EL, Vicentini JR, Johnson AH, Torriani M. Hallux saltans due to stenosing tenosynovitis of flexor hallucis longus: dynamic sonography and arthroscopic findings. Skeletal Radiol 2018:47:747-750.

75. Ahmad M, Tsang K, Mackenney PJ, Adedapo AO. Tarsal tunnel syndrome: a literature review. Foot Ankle Surg 2012;18:149-152.

76. Nagaoka M, Matsuzaki H. Ultrasonography in tarsal tunnel syndrome. J Ultrasound Med 2005;24:1035-1040.

77. Kerr R, Frey C. MR imaging in tarsal tunnel syndrome. J Comput Assist Tomogr 1991;15:280-286

78. Fantino 0. Role of ultrasound in posteromedial tarsal tunnel syndrome: 81 cases. J Ultrasound 2014;17:99-112.

79. Lau JT, Daniels TR. Tarsal tunnel syndrome: a review of the literature. Foot Ankle Int 1999:20:201-209.

80. Takakura Y, Kitada C, Sugimoto K, Tanaka Y, Tamai S. Tarsal tunnel syndrome: causes and results of operative treatment. J Bone Joint Surg Br 1991;73:125-128.

81. Nagaoka M, Satou K. Tarsal tunnel syndrome caused by ganglia. J Bone Joint Surg Br 1999;81:607-610.

82. Wittmayer BC, Freed L. Diagnosis and surgical management of flexor digitorum accessorius longus-induced tarsal tunnel syndrome. J Foot Ankle Surg 2007;46:484-487.

83. Lee SJ, Jacobson JA, Kim SM, Fessell D, Jiang Y, Dong Q, et al. Ultrasound and MRI of the peroneal tendons and associated pathology. Skeletal Radiol 2013;42:1191-1200.

84. Saxena A, Cassidy A. Peroneal tendon injuries: an evaluation of 49 tears in 41 patients. J Foot Ankle Surg 2003;42:215-220.

85. Pesquer L, Guillo S, Poussange N, Pele E, Meyer P, Dallaudiere B. 
Dynamic ultrasound of peroneal tendon instability. $\mathrm{Br}$ J Radiol 2016;89:20150958.

86. Taljanovic MS, Alcala JN, Gimber LH, Rieke JD, Chilvers MM, Latt LD. High-resolution US and MR imaging of peroneal tendon injuries. Radiographics 2015;35:179-199.

87. Neustadter J, Raikin SM, Nazarian LN. Dynamic sonographic evaluation of peroneal tendon subluxation. AJR Am J Roentgenol 2004; 183:985-988.

88. Khoury V, Cardinal E, Bureau NJ. Musculoskeletal sonography: a dynamic tool for usual and unusual disorders. AJR Am J Roentgenol 2007;188:W63-W73.

89. Bianchi S, Becciolini M. Ultrasound features of ankle retinacula: normal appearance and pathologic findings. J Ultrasound Med 2019;38:3321-3334.

90. Klein MA, Spreitzer AM. MR imaging of the tarsal sinus and canal: normal anatomy, pathologic findings, and features of the sinus tarsi syndrome. Radiology 1993;186:233-240.

91. Helgeson K. Examination and intervention for sinus tarsi syndrome. N Am J Sports Phys Ther 2009;4:29-37.

92. Arshad Z, Bhatia M. Current concepts in sinus tarsi syndrome: a scoping review. Foot Ankle Surg 2021;27:615-621.

93. Klausner VB, McKeigue ME. The sinus tarsi syndrome: a cause of chronic ankle pain. Phys Sportsmed 2000;28:75-80.
94. Soliman SB, Spicer PJ, van Holsbeeck MT. Sonographic and radiographic findings of posterior tibial tendon dysfunction: a practical step forward. Skeletal Radiol 2019;48:11-27.

95. Bianchi S, Droz L, Lups Deplaine C, Dubois-Ferriere V, Delmi M. Ultrasonography of the sural nerve: normal and pathologic appearances. J Ultrasound Med 2018;37:1257-1265.

96. Sam RC, Silverman SH, Bradbury AW. Nerve injuries and varicose vein surgery. Eur J Vasc Endovasc Surg 2004;27:113-120.

97. Majewski M, Rohrbach M, Czaja S, Ochsner P. Avoiding sural nerve injuries during percutaneous Achilles tendon repair. Am J Sports Med 2006;34:793-798.

98. Belsack D, Jager T, Scafoglieri A, Vanderdood K, Van Hedent E, Vanhoenacker $F$, et al. Ultrasound of the sural nerve: normal anatomy on cadaveric dissection and case series. Eur J Radiol 2013;82:1953-1958.

99. Rbia N, Nijhuis TH, Roukema GR, Selles RW, van der Vlies CH, Hovius SE. Ultrasound assessment of the sural nerve in patients with neuropathic pain after ankle surgery. Muscle Nerve 2018;57:407-413.

100. Arni $D$, Lambert V, Delmi M, Bianchi S. Insufficiency fracture of the calcaneum: sonographic findings. I Clin Ultrasound 2009;37:424427. 